Supporting Information

\title{
Nanoparticle Assembly Induced Ligand Interactions for Enhanced Electrocatalytic $\mathrm{CO}_{2}$ Conversion
}

Sunmoon Yu, ${ }^{1,3, \dagger}$ Dohyung Kim, ${ }^{1,2,3, \dagger}$ Zhiyuan $\mathrm{Qi}^{3}{ }^{3}$ Sheena Louisia, ${ }^{2,3}$ Yifan Li, ${ }^{2,3}$ Gabor A. Somorjai, ${ }^{2,4}$ and Peidong Yang ${ }^{1,2,3,5 *}$

${ }^{1}$ Department of Materials Science and Engineering, University of California, Berkeley, CA 94720, USA.

${ }^{2}$ Department of Chemistry, University of California, Berkeley, CA 94720, USA.

${ }^{3}$ Chemical Sciences Division, Lawrence Berkeley National Laboratory, Berkeley, CA 94720, USA.

${ }^{4}$ Materials Sciences Division, Lawrence Berkeley National Laboratory, Berkeley, CA 94720, USA.

${ }^{5}$ Kavli Energy NanoScience Institute, Berkeley, CA 94720, USA.

†These authors contributed equally to this work.

Correspondence to: p_yang@berkeley.edu 


\section{Methods}

Silver nanoparticle (NP) synthesis. Ag NPs were similarly synthesized following the procedure previously reported by our group. ${ }^{1}$ In order to control the size of the NPs, only the molar ratio of metal precursor (silver(I) acetate, Sigma-Aldrich, 99.99\%) to ligand (tetradecylphosphonic acid, or TDPA, Sigma-Aldrich, 97\%) was varied. For $4 \mathrm{~nm} \mathrm{Ag} \mathrm{NP} \mathrm{synthesis,} 0.25 \mathrm{mmol}$ of silver acetate and $0.50 \mathrm{mmol}$ of TDPA were dissolved in $10 \mathrm{ml}$ of trioctylamine (Sigma-Aldrich, 98\%), while $0.75 \mathrm{mmol}$ and $0.13 \mathrm{mmol}$, respectively, for $8 \mathrm{~nm} \mathrm{Ag} \mathrm{NP}$ synthesis. Reaction conditions, washing procedures, and post size selection steps were identical to our previous report. ${ }^{1}$

Electrode preparation. Electrodes were prepared by drop-casting NP solution (4 and 8 nm NPs dispersed in hexane) on a carbon paper support with a geometric area of $1 \mathrm{~cm}^{2}$ (Sigracet, 29 AA). The concentration of the NP solution was determined by using inductively coupled plasma optical emission spectrometry (Perkin Elmer Optima 7000 DV).

In order to fix the initial total amount of ligands on each electrode, different mass loadings were used for the 4 and $8 \mathrm{~nm}$ cases (19.2 and $38.4 \mu \mathrm{g}$, respectively). We assumed the footprint of TDPA ligands on the NP surface is identical $\left(27 \AA^{2}\right)\left(\right.$ ref. $\left.^{2}\right)$, irrespective of the NP size, and therefore fixed the total surface area of the NPs deposited on each carbon paper support (also the total projected area of the NPs, as both scale with the square of the NP radius). Due to a larger surface-to-volume ratio of $4 \mathrm{~nm} \mathrm{Ag} \mathrm{NPs}$, less mass loading was used for the $4 \mathrm{~nm}$ case as specified above.

For isolated NP configurations, the total particle number of assembled $4 \mathrm{~nm} \mathrm{Ag} \mathrm{NPs} \mathrm{loaded}$ on a carbon paper was reduced by a factor of 15 , and this reduced total particle number was also applied to the isolated $8 \mathrm{~nm} \mathrm{Ag} \mathrm{NP} \mathrm{configuration.}$

Electrocatalytic testing. Electrocatalytic measurements were carried out in a customized, H-cell type electrochemical cell where two compartments were separated by an anion exchange membrane (Selemion, AMV). Ag/AgCl $3 \mathrm{M} \mathrm{KCl} \mathrm{(World} \mathrm{Precision} \mathrm{Instruments)} \mathrm{and} \mathrm{Pt} \mathrm{wire} \mathrm{were}$ used as a reference and a counter electrode, respectively. $0.1 \mathrm{M} \mathrm{KHCO}_{3}$ electrolyte was prepared by purging $0.05 \mathrm{M} \mathrm{K}_{2} \mathrm{CO}_{3}$ (Alfa Aesar, 99.997\%, trace metals basis) solution with $\mathrm{CO}_{2}$ gas (Praxair, 5.0 UHP) overnight ( $\mathrm{pH}$ 6.8). For $0.1 \mathrm{M} \mathrm{CsHCO}_{3}$ electrolyte, $0.05 \mathrm{M} \mathrm{Cs}_{2} \mathrm{CO}_{3}$ was used (Sigma-Aldrich, 99.995\%, trace metals basis). Electrolyte was saturated with $\mathrm{CO}_{2}$ gas prior to each electrocatalytic testing, and kept bubbled at a flow rate of $20 \mathrm{sccm}$ with stirring during $\mathrm{CO}_{2}$ electrocatalysis.

For electrocatalytic testing, potentiostatic (i.e., potential-controlled) experiments were performed, and electrode potentials were converted to the reversible hydrogen electrode (RHE) scale using $\mathrm{E}(\mathrm{vs}$. RHE) $=\mathrm{E}(\mathrm{vs} . \mathrm{Ag} / \mathrm{AgCl} 3 \mathrm{M} \mathrm{KCl})+0.210+0.0591 \times \mathrm{pH}$. Linear sweep voltammetry (LSV) and cyclic voltammetry (CV) were conducted at a scan rate of $50 \mathrm{mV} / \mathrm{s}$. For all the electrochemical testing, $84 \%$ of ohmic loss was compensated by the potentiostat (Biologic) while the remaining $16 \%$ was manually post-corrected.

Gas products were quantified by a gas chromatograph (SRI) equipped with a thermal conductivity detector and a flame ionization detector. Faradaic efficiencies (FEs) were calculated by dividing the amount of charge consumed for each product by the total charge passed, and total, $\mathrm{CO}$, and $\mathrm{H}_{2} \mathrm{FE}$ values are available in Table $\mathrm{S} 1$. Selectivity reported in this work is normalized FE (liquid products are not considered, as FEs for liquid products were negligibly small, less than $0.2 \%)$. 
Removal of the ligand layer and thus the NOLI structure from Ag-NOLI catalysts was achieved by rinsing electrodes after $\mathrm{CO}_{2}$ electrolysis with concentrated $\mathrm{KOH}$. Subsequently, the NOLI removed electrodes were rinsed with deionize water, and transferred to the electrochemical cell to test electrocatalytic performance of the NOLI removed catalyst.

Electrochemically active surface area (ECSA) measurement. $\mathrm{Pb}$ underpotential deposition (UPD) method was used to measure ECSA of Ag-NOLI catalysts. Cyclic voltammetry (CV) was conducted from -0.10 to $-0.45 \mathrm{~V}$ vs. $\mathrm{Ag} / \mathrm{AgCl} 1 \mathrm{M} \mathrm{KCl}(\mathrm{CH}$ Instruments) with a scan rate of 50 $\mathrm{mV} / \mathrm{s}$ in $3 \mathrm{mM} \mathrm{Pb}\left(\mathrm{ClO}_{4}\right)_{2}, 10 \mathrm{mM} \mathrm{HClO}_{4}$, and $100 \mathrm{mM} \mathrm{NaClO}_{4}$ solution. Ag foil with a geometric area of $1 \mathrm{~cm}^{2}$ was used as a reference sample, and its $\mathrm{Pb}$ stripping charge $\left(361.7 \mu \mathrm{C} / \mathrm{cm}^{2}\right)$ was used to calculate ECSA of Ag-NOLI catalysts.

Structural characterization. Transmission electron microscopy (TEM, Hitachi H-7650) and scanning electron microscopy (SEM, Zeiss Supra 55 VP) were used to characterize Ag NPs and evolved catalysts after $\mathrm{CO}_{2}$ electrocatalysis. Powder X-ray diffraction (Bruker D8) patterns were obtained using a monochromatic $\mathrm{Cu} \mathrm{K} \alpha$ source, and crystallite size of NP catalysts after $\mathrm{CO}_{2}$ electrolysis was estimated by using the Scherrer equation ( 0.94 was used for the Scherrer constant). The Voigt function was used to fit the Ag111 peak and obtain peak width (i.e., full width at half maximum). X-ray photoelectron spectroscopy (XPS, Thermo Scientific K-Alpha) was conducted using monochromatic Al K $\alpha$ radiation. X-ray spot size of $400 \mu \mathrm{m}$ and pass energy of $50 \mathrm{eV}$ were consistently used for the measurement. Shirley background was used for background subtraction. Ligand coverage on the NP surface was estimated from the atomic ratio of P to Ag (see Figure S18 and its caption for more details).

Sum frequency generation (SFG) vibrational spectroscopy. Since a flat support is required for SFG measurement, glassy carbon electrodes (GCEs) (Ted Pella) were used in place of carbon paper supports. Ag NPs were similarly drop-cast on the GCE with a geometric area of $1 \mathrm{~cm}^{2}$, and the concentration of Ag NP solution was controlled to achieve 5 and 100\% coverage for initial isolated and assembled Ag NP configurations, respectively. As a control experiment, crystalline TDPA and TDPA-coated Ag film were used. For the TDPA coating, flat, reflective Ag film sputtered on cover glass was immersed in $1 \mathrm{mM}$ TDPA ethanolic solution overnight, and adequately rinsed with ethanol and deionized water.

A picosecond Nd:YAG pump laser system (PL2250, Ekspla) was used with a repetition rate of $20 \mathrm{~Hz}$ and an average pulse of $25 \mathrm{~mJ}$. An optical parametric generator and amplifier system (LaserVision) converted the 1,064 nm laser beam to a visible beam at $532 \mathrm{~nm}$ and a tunable midinfrared beam between 2,200 and 4,000 $\mathrm{cm}^{-1}$. The two beams overlapped spatially and temporally on the sample surface to generate the SFG signal, with pulse energies of 200 and $100 \mu \mathrm{J}$, respectively. Each SFG spectrum is an average of 8-10 scans with a wavenumber step of $4 \mathrm{~cm}^{-1}$. The polarization combination used to probe the perpendicular dipole moments is SSP (SFGvisible-infrared).

For quantitative analysis, SFG spectra were fitted to a series of coherently added Lorentzian line shapes:

$$
I_{S F G}\left(\omega_{I R}\right) \propto\left|A_{N R} e^{i \phi}+\sum_{j=1}^{N} \frac{B_{j} \Gamma_{j}}{\left(\omega_{I R}-\omega_{j}\right)+i \Gamma_{j}}\right|^{2}
$$


with each vibrational mode $j$ described by amplitude $B_{j}$, line width $\Gamma_{j}$, and frequency $\omega_{j}\left(\right.$ ref. $\left.^{3}\right)$. The first term on the right-hand side of the equation accounts for the non-resonant part of the response with amplitude $A_{\mathrm{NR}}$ and phase $\phi$ with respect to the vibrationally resonant part. ${ }^{3}$ For each vibrational mode $j, I_{j}=\left|\mathrm{B}_{j}\right|^{2}$, and the intensity ratio for methylene $\left(\mathrm{CH}_{2}\right)$ and methyl $\left(\mathrm{CH}_{3}\right)$ symmetric stretch modes (i.e., $\mathrm{d}^{+} / \mathrm{r}^{+}$) were obtained from the fitting as a semi-quantitative measure of the degree of structural order in the ligand chains.

Electrochemical impedance spectroscopy (EIS). EIS measurements were performed in the same electrochemical setup as the electrocatalytic testing. A sinusoidal potential (e.g., $-0.68 \mathrm{~V}$ vs. RHE with a sinus amplitude of $10 \mathrm{mV}$ ) was applied in the frequency range of $100 \mathrm{kHz}$ to $100 \mathrm{mHz}$ with three measures for each frequency.

Impedance data were fitted in a similar fashion as previously reported ${ }^{1}$ using a five-element equivalent electrical circuit, consisting of solution resistance $\left(\mathrm{R}_{\mathrm{s}}\right)$, double layer capacitance $\left(\mathrm{C}_{\mathrm{dl}}\right)$, charge transfer resistance $\left(\mathrm{R}_{\mathrm{ct}}\right)$, pseudocapacitance $\left(\mathrm{C}_{\mathrm{pseudo}}\right)$ and charge transfer resistance for pseudocapacitance $\left(\mathrm{R}_{\text {pseudo }}\right.$ ) (see Figure $7 \mathrm{a}$ inset or $\mathrm{S} 20 \mathrm{a}$ for the equivalent circuit diagram). For actual fitting, a constant phase element (Q) was substituted for an ideal capacitor element for the double layer capacitance. For specific capacitance (i.e., $\mu \mathrm{F} / \mathrm{cm}^{2}$ ) calculations, total surface area for Ag particles, obtained after removal of the ligand layer from Ag-NOLI catalysts, was used to take into account all physical interfacial area at the Ag particle surface. 

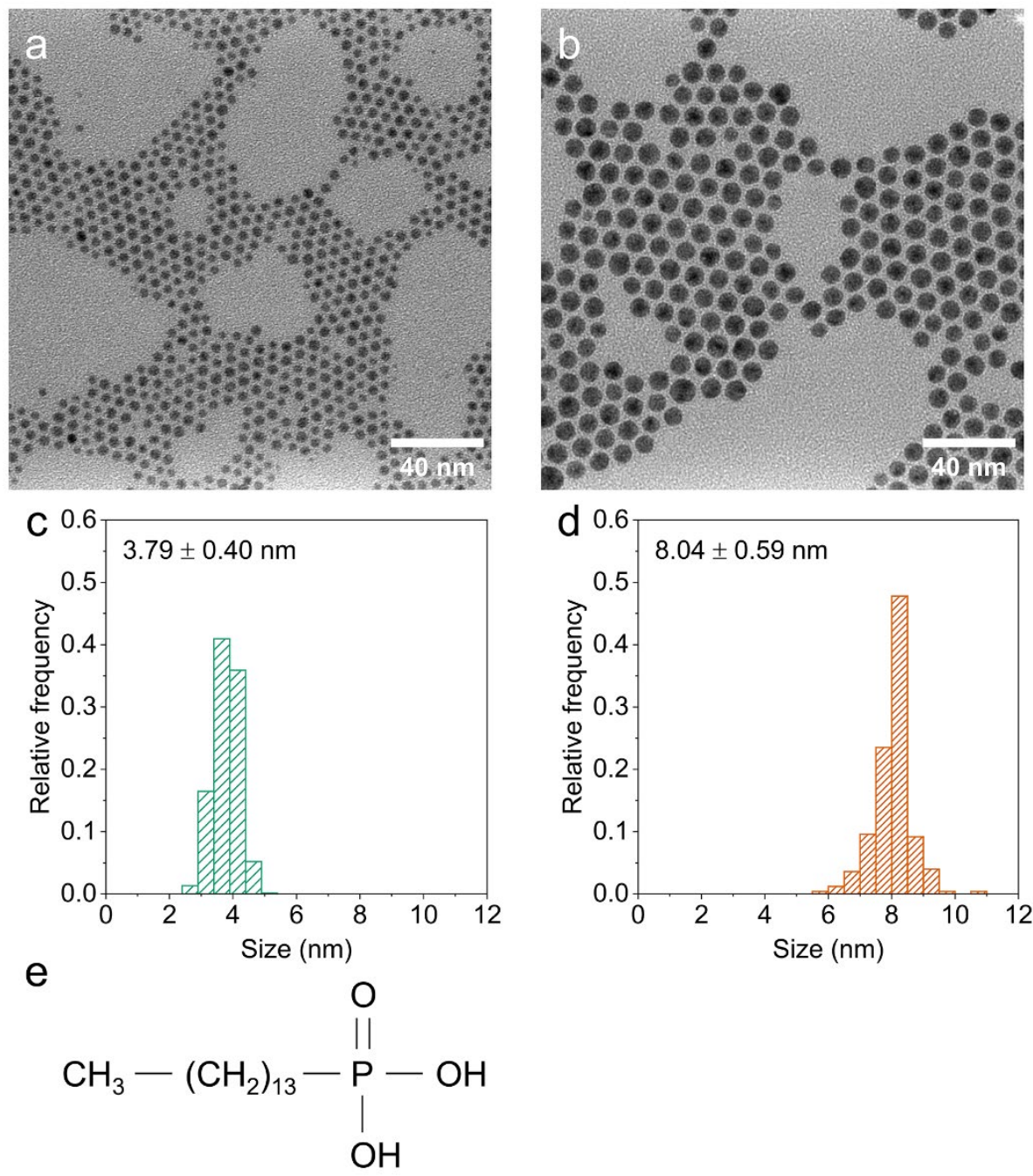

Figure S1. a, b, TEM images of as-synthesized 4 and $8 \mathrm{~nm} \mathrm{Ag} \mathrm{NPs.} \mathrm{c,} \mathrm{d,} \mathrm{Corresponding} \mathrm{size}$ distribution of the Ag NPs. e, Chemical structure of the TDPA ligand used for Ag NP synthesis. 

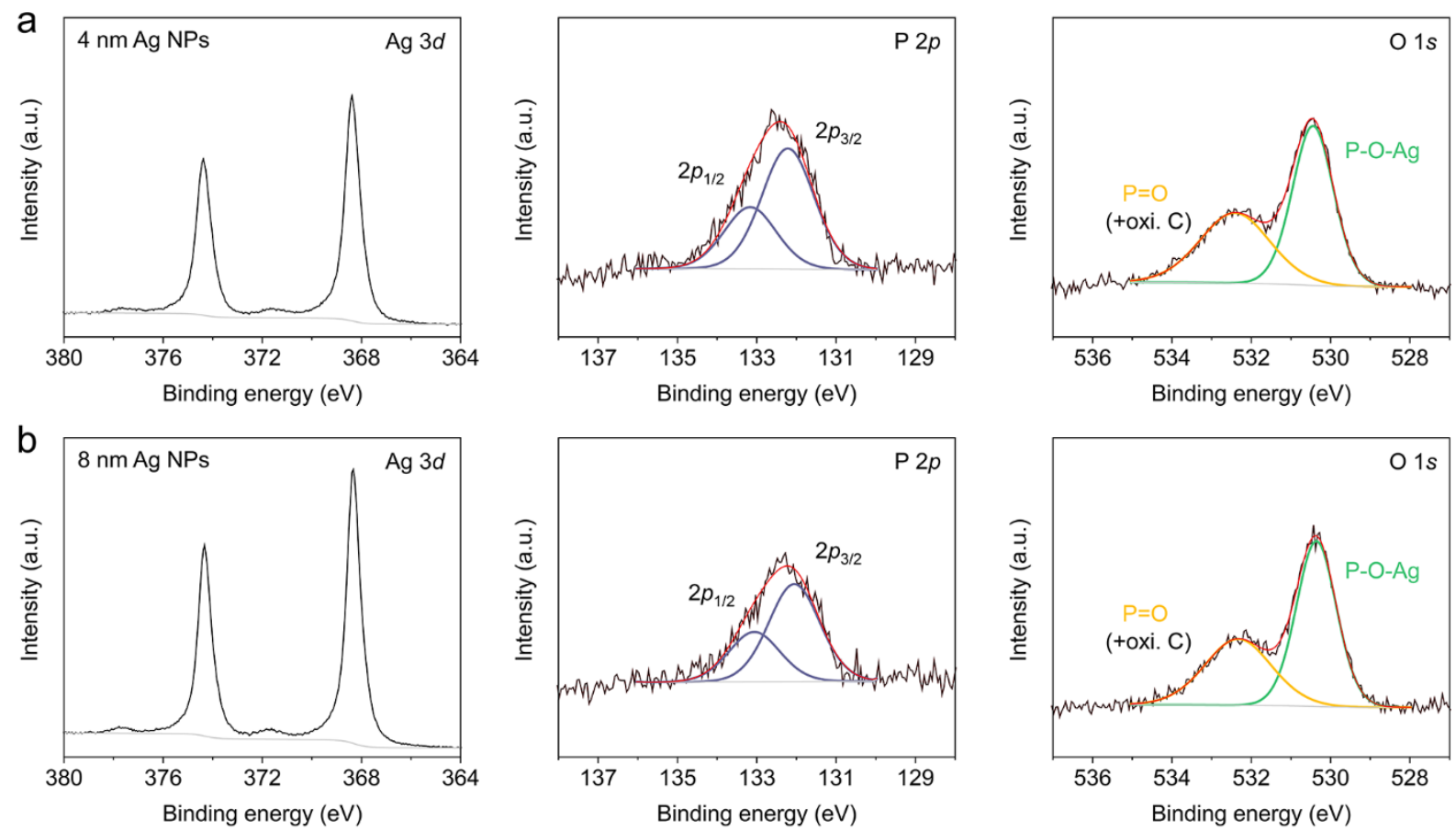

C

\begin{tabular}{|c|cccc|cccc|}
\hline & \multicolumn{4}{|c|}{$4 \mathrm{~nm} \mathrm{Ag} \mathrm{NPs}$} & \multicolumn{4}{c|}{$8 \mathrm{~nm} \mathrm{Ag} \mathrm{NPs}$} \\
\hline & $\mathrm{Ag}$ & $\mathrm{P}$ & $\mathrm{P}-\mathrm{O}-\mathrm{Ag}$ & $\mathrm{P}=\mathrm{O}$, oxi. C & $\mathrm{Ag}$ & $\mathrm{P}$ & $\mathrm{P}-\mathrm{O}-\mathrm{Ag}$ & $\mathrm{P}=\mathrm{O}$, oxi. C \\
\hline at.\% & $53.5 \pm 2.8$ & $7.3 \pm 0.3$ & $13.6 \pm 0.2$ & $11.8 \pm 1.0$ & $61.2 \pm 4.1$ & $5.8 \pm 0.2$ & $10.6 \pm 0.3$ & $8.2 \pm 0.5$ \\
Ratio & - & 1.0 & $1.9 \pm 0.1$ & - & - & 1.0 & $1.8 \pm 0.1$ & - \\
\hline
\end{tabular}

Figure S2. a, b, XPS spectra (Ag $3 d$, P $2 p$, and $\mathrm{O} 1 s)$ of as-synthesized 4 and $8 \mathrm{~nm} \mathrm{Ag} \mathrm{NPs.} \mathrm{P} 2 p$ peaks are deconvoluted into $2 p_{1 / 2}$ and $2 p_{3 / 2}$, while $\mathrm{O} 1 s$ peaks are deconvoluted into two peaks representing two different oxygen species in the phosphonate head group of the TDPA ligand (P$\mathrm{O}-\mathrm{Ag}$ and $\mathrm{P}=\mathrm{O}$ ). c, Table showing atomic percent of each element and atomic ratio of $\mathrm{P}$ to $\mathrm{P}-\mathrm{O}-$ Ag. The atomic ratios of $\mathrm{P}$ to $\mathrm{P}-\mathrm{O}-\mathrm{Ag}$ for both cases are close to 2, suggesting the TDPA ligands are initially chemically bound on the Ag NP surface in a bidentate mode. Also, note that the atomic ratio of $\mathrm{P}-\mathrm{O}-\mathrm{Ag}$ to $\mathrm{P}=\mathrm{O}$ does not give 2 as the $\mathrm{P}=\mathrm{O}$ region contains overlapping oxygen species from the carbon support itself. 

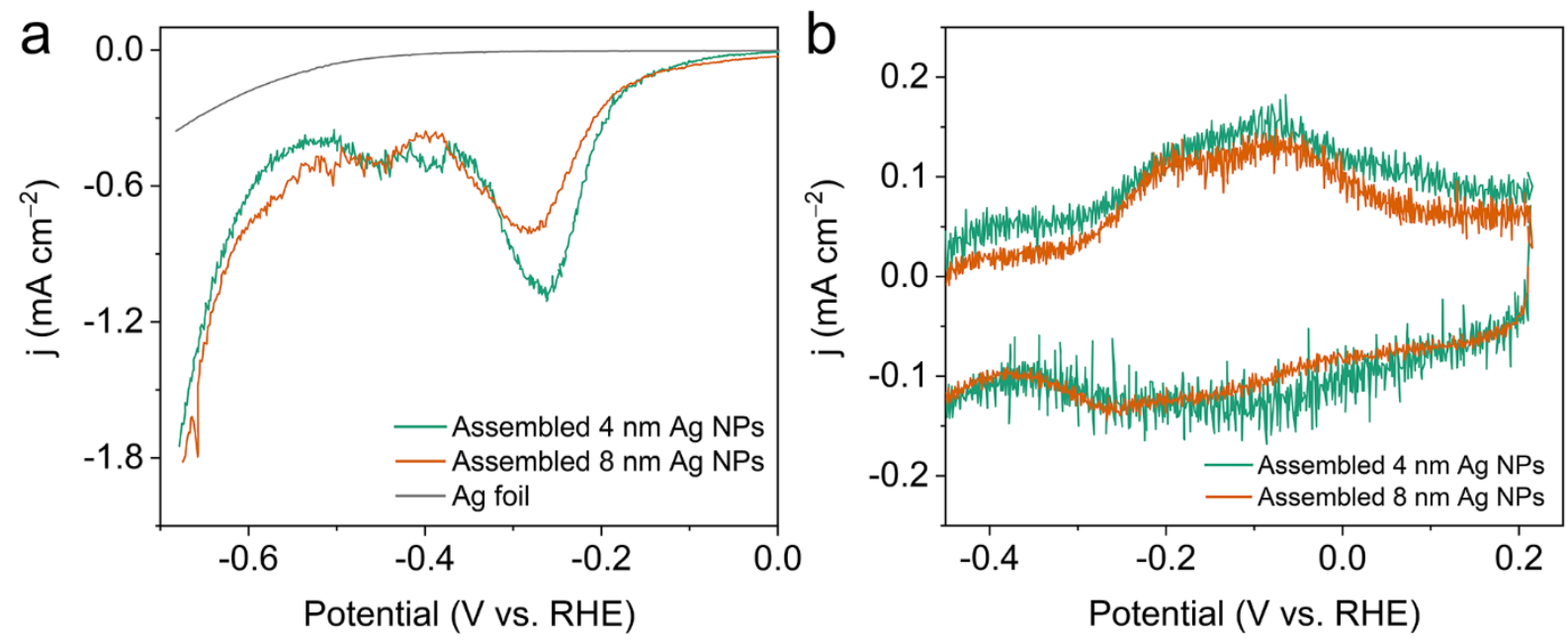

Figure S3. a, LSV of assembled 4 and $8 \mathrm{~nm} \mathrm{Ag} \mathrm{NPs} \mathrm{and} \mathrm{Ag} \mathrm{foil.} \mathrm{b,} \mathrm{Subsequent} \mathrm{CV} \mathrm{scans} \mathrm{of}$ assembled 4 and $8 \mathrm{~nm} \mathrm{Ag} \mathrm{NPs} \mathrm{after} \mathrm{the} \mathrm{first} \mathrm{LSV} \mathrm{(i.e.,} \mathrm{the} \mathrm{second} \mathrm{scan).} \mathrm{A} \mathrm{cathodic} \mathrm{peak}$ exclusively observed for assembled Ag NPs in LSV arises from reductive dissociation of NP surface ligands under negative bias.

Theoretical reductive charge for complete ligand dissociation is estimated to be $3.25 \mathrm{mC}$ for both systems whose total NP loading was controlled to arrive at identical total NP surface area and hence total amount of surface ligands (the footprint of the ligand assumed to be $27 \AA^{2}$ ). ${ }^{2}$ On the other hand, empirical reductive charge passed for the collective ligand dissociation can be calculated by measuring the reductive peak area in LSV (a): 3.21 and $2.00 \mathrm{mC}$ for the assembled 4 and $8 \mathrm{~nm} \mathrm{Ag} \mathrm{NPs,} \mathrm{respectively.} \mathrm{In} \mathrm{comparison} \mathrm{to} \mathrm{the} \mathrm{assembled} 4 \mathrm{~nm} \mathrm{Ag} \mathrm{NPs,} \mathrm{the} \mathrm{assembled} 8$ $\mathrm{nm}$ Ag NPs shows relatively smaller reductive charge passed for the initial dissociation of the chemisorbed ligands. In addition, for the assembled $8 \mathrm{~nm} \mathrm{Ag} \mathrm{NPs,} \mathrm{the} \mathrm{reversible}$ adsorption/desorption features of the ligand layer formed by the initial dissociation during LSV in the subsequent $\mathrm{CV}$ scans show a relatively smaller area $(0.32 \mathrm{mC}$ compared to $0.42 \mathrm{mC}$ for the assembled $4 \mathrm{~nm} \mathrm{Ag} \mathrm{NPs).}$ 

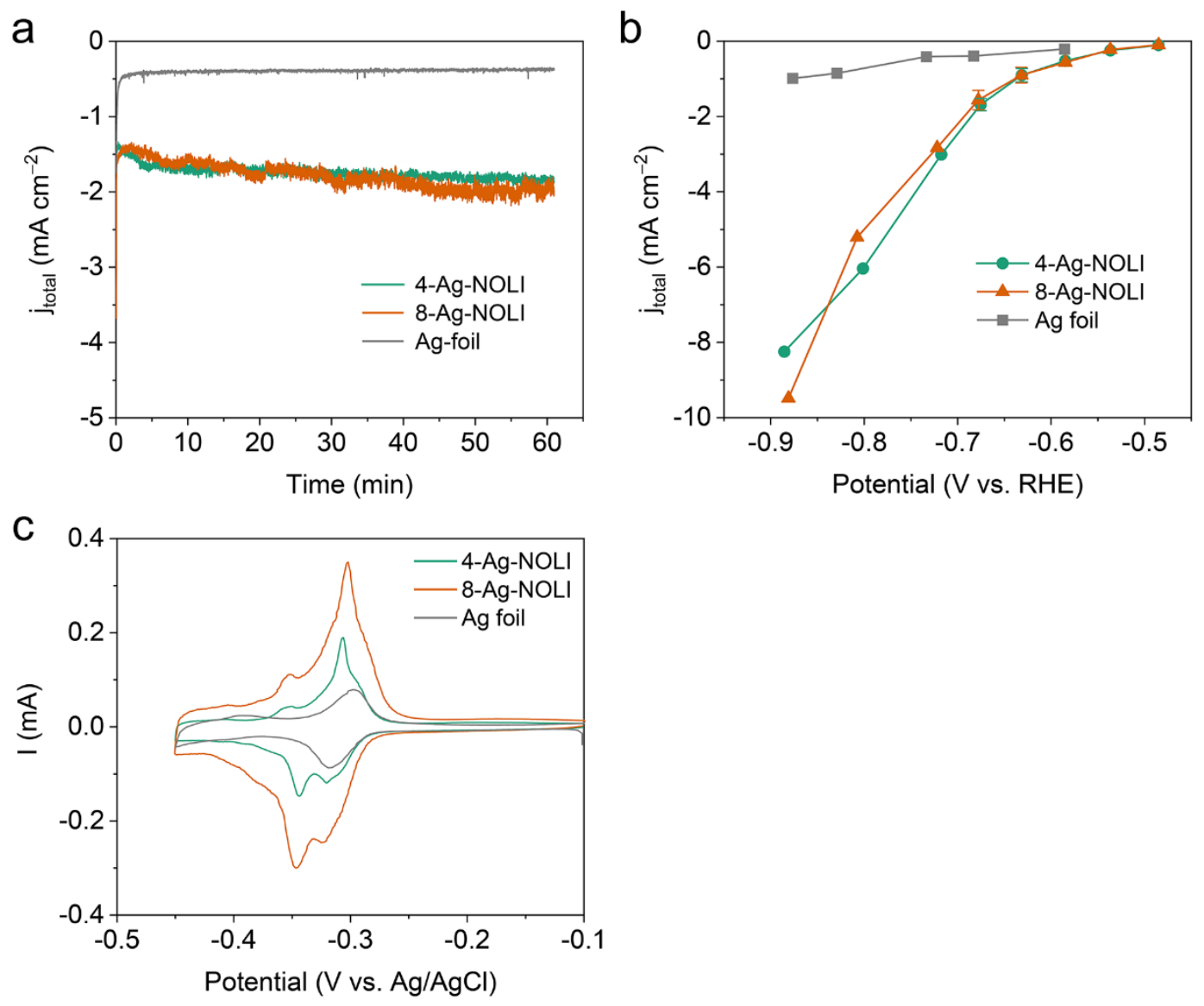

Figure S4. a, Representative potentiostatic current density-time plots of 4-Ag-NOLI, 8-Ag-NOLI and $\mathrm{Ag}$ foil at $-0.68 \mathrm{~V}$ vs. RHE in $0.1 \mathrm{M} \mathrm{KHCO}_{3}$ (hereafter, X-Ag-NOLI refers to Ag-NOLI catalyst derived from the assembled Ag NPs with an initial size of X nm). b. Averaged current density of Ag-NOLI catalysts and Ag foil as a function of applied potential. $\mathbf{c}, \mathrm{Pb}$ UPD and anodic stripping curves of Ag-NOLI catalysts and Ag foil to obtain electrochemically active surface area. 

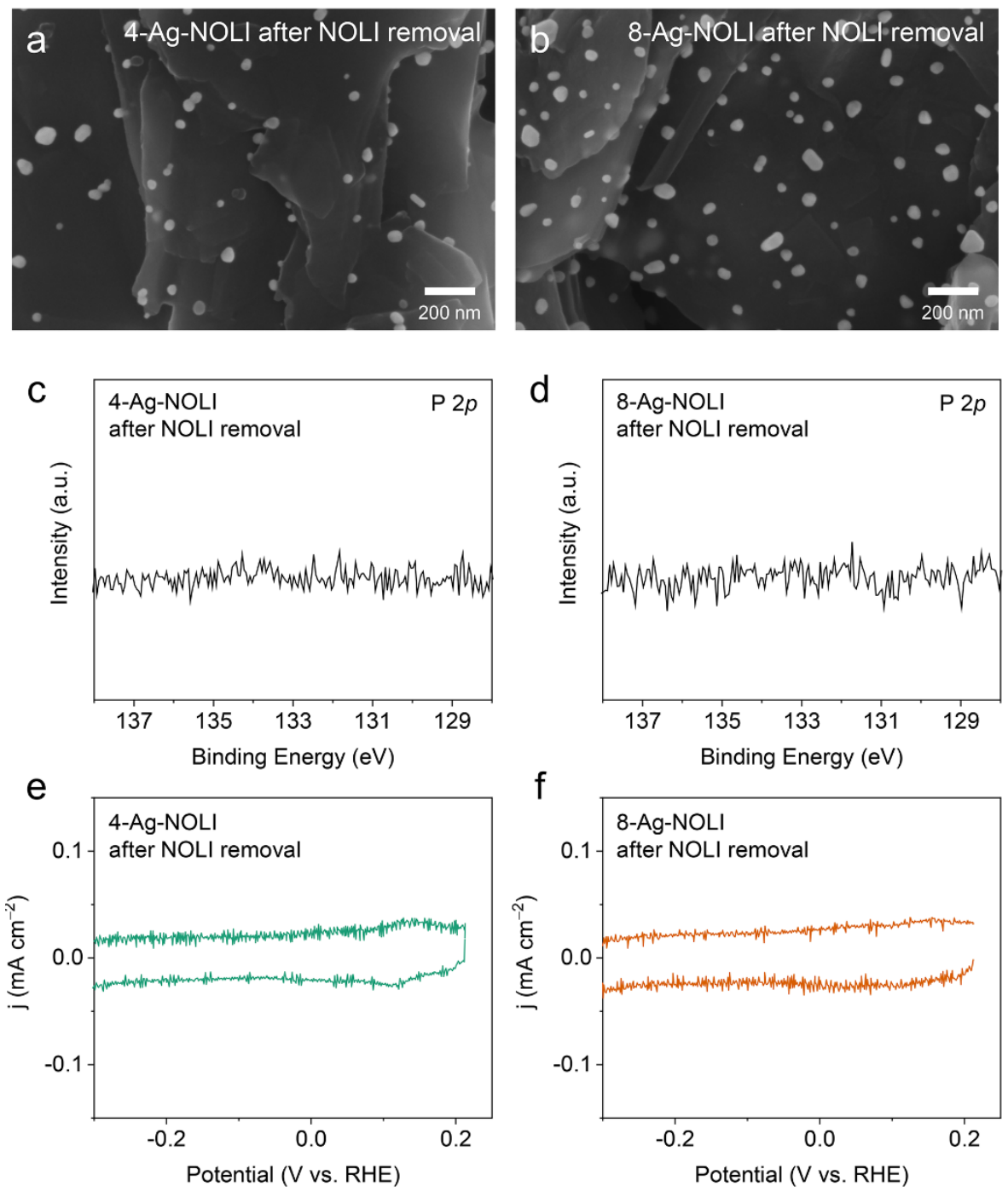

Figure S5. a, b, SEM images of 4-Ag-NOLI and 8-Ag-NOLI catalysts after NOLI removal. Overall size and shape of the particles do not change when the ligands are removed. $\mathbf{c}, \mathbf{d}$, XPS (P $2 p$ ) spectra of Ag-NOLI catalysts after NOLI removal. The absence of $\mathrm{P} 2 p$ peak verifies the effective removal of the ligand layer and therefore the NOLI from the Ag-NOLI catalysts. e, $\mathbf{f}, \mathrm{CV}$ scans of Ag-NOLI catalysts after NOLI removal. The absence of the reversible adsorption/desorption features in the CV scans offers further support for the NOLI removal. 

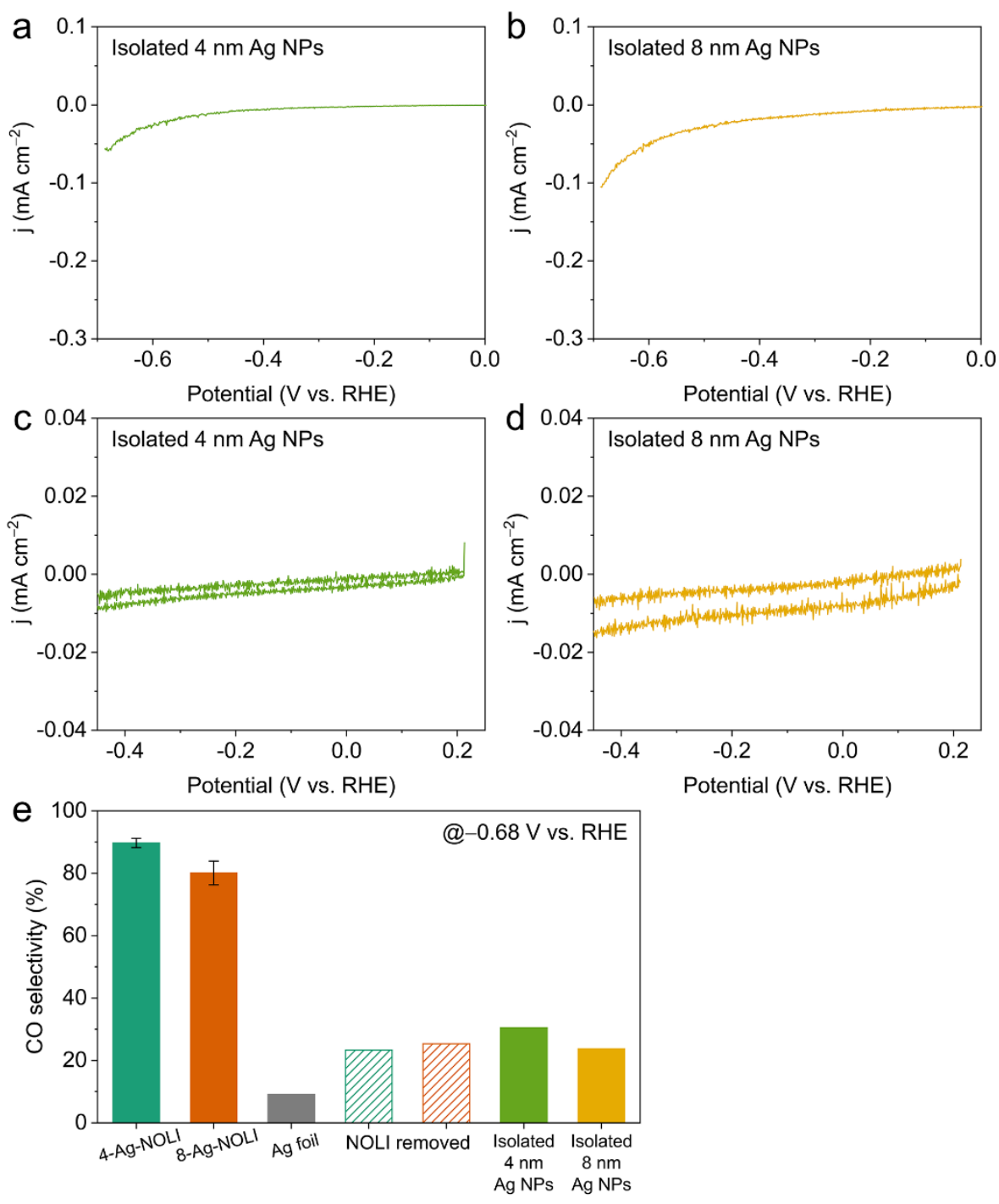

Figure S6. a, b, LSV curves of isolated 4 and $8 \mathrm{~nm} \mathrm{Ag} \mathrm{NPs.} \mathrm{c,} \mathrm{d,} \mathrm{Subsequent} \mathrm{CV} \mathrm{scans} \mathrm{of} \mathrm{the}$ isolated 4 and $8 \mathrm{~nm} \mathrm{Ag} \mathrm{NPs} \mathrm{after} \mathrm{the} \mathrm{first} \mathrm{LSV.} \mathrm{e,} \mathrm{CO} \mathrm{selectivity} \mathrm{comparison} \mathrm{at}-0.68 \mathrm{~V}$ vs. RHE in $0.1 \mathrm{M} \mathrm{KHCO}_{3}$ (hatched green and brown columns represent 4-Ag-NOLI and 8-Ag-NOLI after the NOLI removal, respectively). The absences of the reductive ligand dissociation peak in the LSV curve and reversible adsorption/desorption features in the subsequent CV scans for isolated Ag NPs (a-d) indicate that the NOLI did not form, a more typical NP catalyst case (i.e., particles capped with ligands). Also, in comparison with the NOLI catalysts, the isolated Ag NPs show a more typical CO selectivity. 

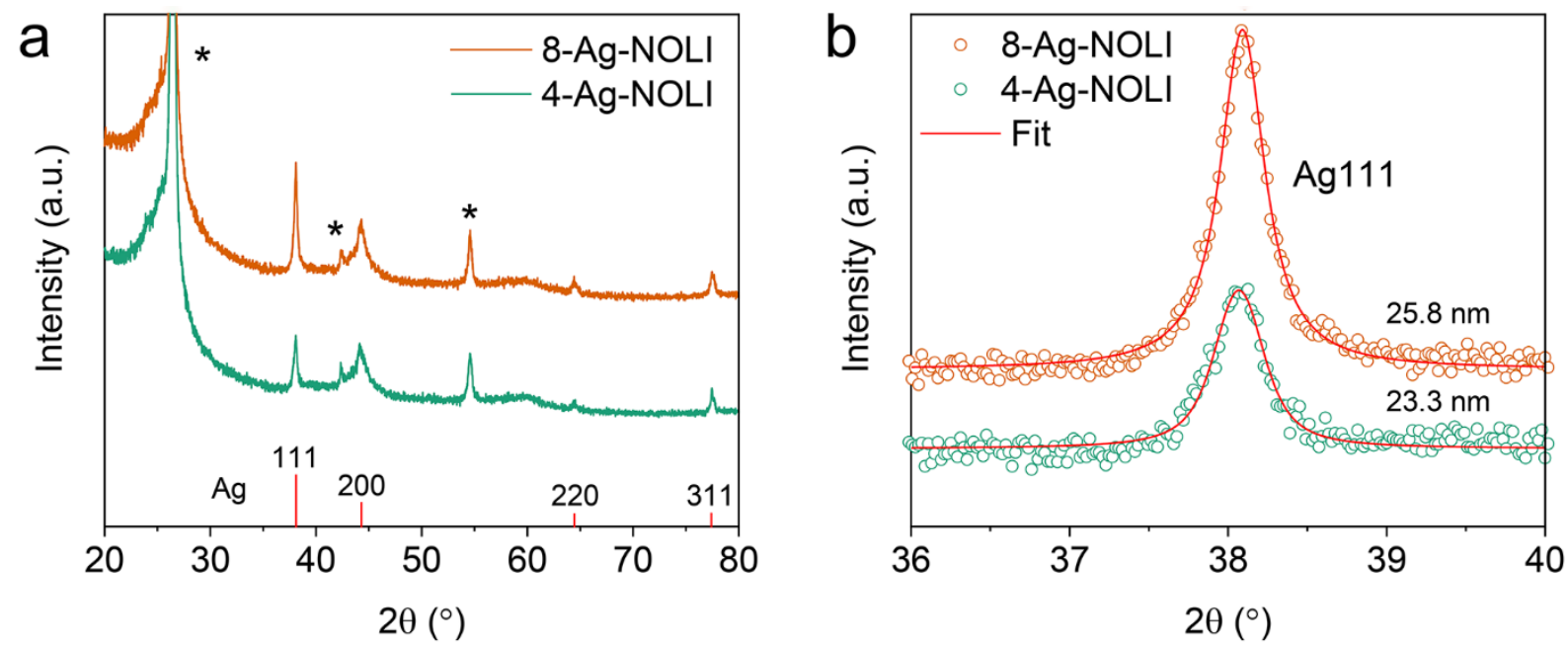

Figure S7. a, XRD patterns of 4-Ag-NOLI and 8-Ag-NOLI after one-hour $\mathrm{CO}_{2}$ electrocatalysis. Asterisks indicate graphite peaks from the carbon paper support. b, Ag111 peak of Ag-NOLI catalysts used for crystallite size estimation from the Scherrer equation (see Methods for more details). 

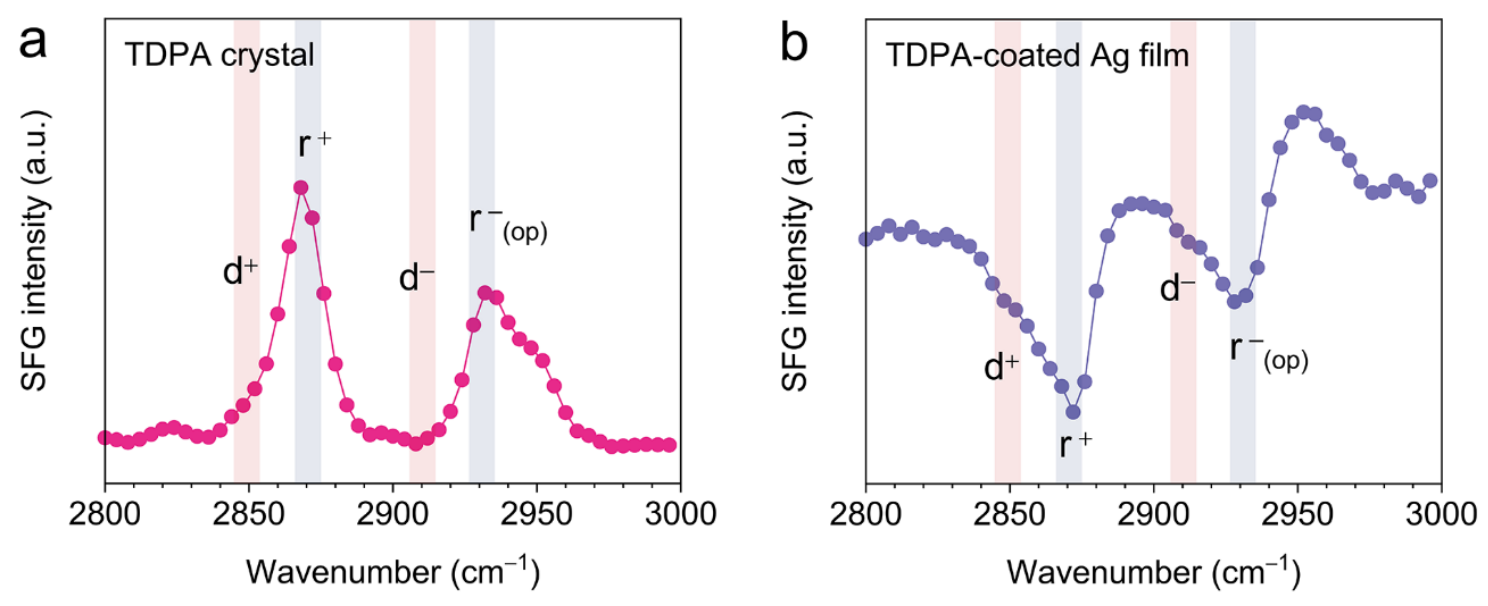

Figure S8. a, b, SFG spectra of crystalline TDPA and TDPA-coated Ag film. Particularly weak $\mathrm{d}^{+}$and $\mathrm{d}^{-}$peaks with respect to $\mathrm{r}^{+}$and $\mathrm{r}^{-}$(op) peaks observed for TDPA crystal (a) indicate that the crystalline TDPA ligands have nearly all-trans conformation. When TDPA was coated on the flat sputtered Ag film (b), the self-assembled monolayers of TDPA also show weak intensities for $\mathrm{d}^{+}$ and $\mathrm{d}^{-}$peaks, suggesting the ligands are dominantly in trans conformation and structurally wellordered. Note that peaks in the SFG spectrum for the TDPA-coated Ag film are reversed due to strong nonlinear signals from the reflective Ag substrate. ${ }^{4-5}$ 


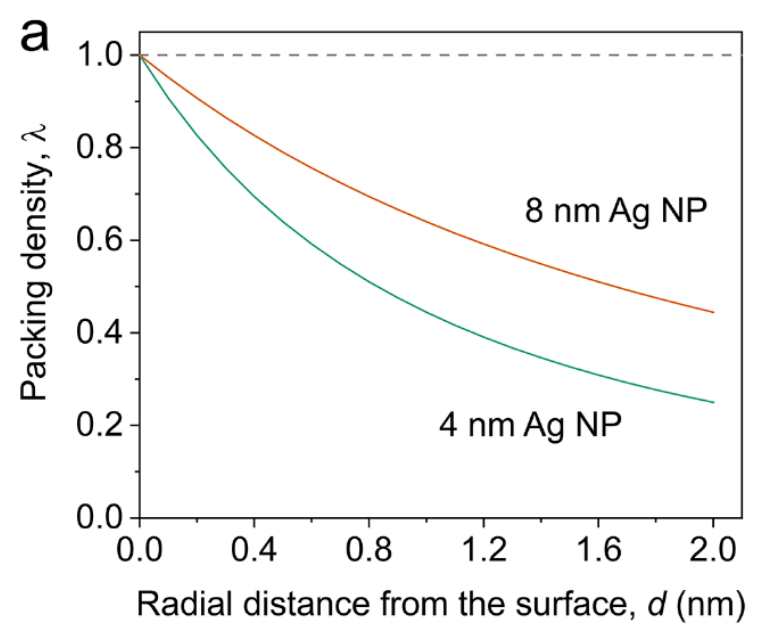

b

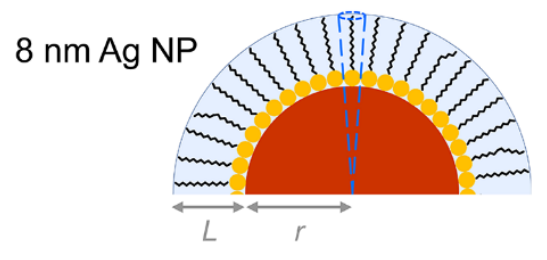

$4 \mathrm{~nm}$ Ag NP

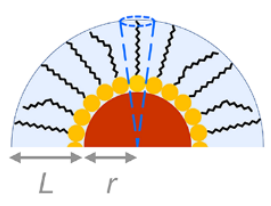

Figure S9. a, Packing density ( $\lambda$ ) of TDPA ligands on 4 and $8 \mathrm{~nm} \mathrm{Ag} \mathrm{NPs} \mathrm{as} \mathrm{a} \mathrm{function} \mathrm{of} \mathrm{distance}$ from the NP surface $(d \leq 2 \mathrm{~nm})$. b, Schematics illustrating a relatively lower packing density of ligands on $4 \mathrm{~nm}$ NP due to its large surface curvature. That is, larger conical volume is available for each ligand, indicated with dashed blue lines ( $L$ is the ligand length, and $r$ is the radius of NPs). The packing density is defined as the ratio of the theoretical cross-sectional area per ligand to the available cross-sectional area per ligand.$^{6-7}$ Packing density of one is assumed at the surface, although it may be less than one (e.g., packing density of alkylthiol ligands on $\operatorname{Ag}(111)$ is generally known to be $\sim 0.98$, but its accurate determination is still challenging). The packing density $(\lambda)$ as a function of radial distance from the surface $(d)$ was calculated using the following equation ${ }^{7}$ :

$$
\lambda(d)=\frac{r^{2}}{(r+d)^{2}} \lambda(0)
$$



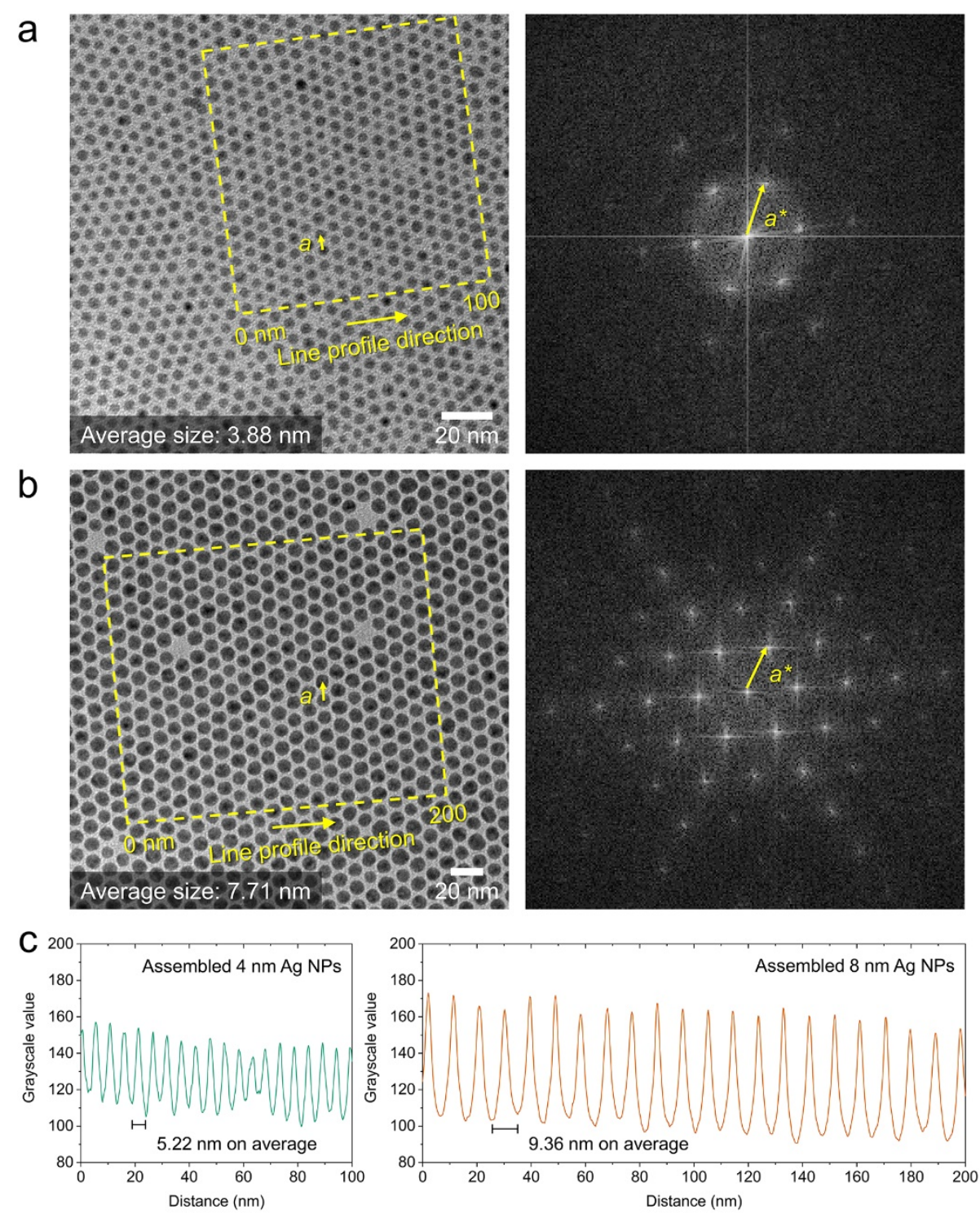

Figure S10. a, b, TEM image and corresponding fast Fourier transform (FFT) of Ag NP assembly on a TEM grid. c, Averaged line profiles from the area marked with a dashed yellow rectangle in each corresponding TEM image (note that the average distances obtained from the line profiles are the distance between two adjacent rows of NPs that is not exactly from center-to-center). The average center-to-center interparticle distance estimated from the line profiles for assembled 4 and $8 \mathrm{~nm} \mathrm{Ag} \mathrm{NPs} \mathrm{were} 6.03$ and $10.81 \mathrm{~nm}$, respectively (actual average size of NPs used for this particular experiment were 3.88 and $7.71 \mathrm{~nm}$ ). Therefore, the average gap between adjacent NPs (that is, center-to-center interparticle distance minus NP size) was 2.15 and $3.10 \mathrm{~nm}$ for the assembled 4 and $8 \mathrm{~nm} \mathrm{Ag} \mathrm{NPs.} \mathrm{Also,} \mathrm{the} \mathrm{average} \mathrm{gap} \mathrm{can} \mathrm{be} \mathrm{determined} \mathrm{from} \mathrm{the} \mathrm{FFT,} \mathrm{which} \mathrm{was}$ 2.22 and $3.16 \mathrm{~nm}$, respectively. Both results not only agree well, but also the average gap for the assembled $4 \mathrm{~nm} \mathrm{Ag} \mathrm{NPs} \mathrm{was} \mathrm{consistently} \mathrm{smaller} \mathrm{than} \mathrm{that} \mathrm{of} \mathrm{the} \mathrm{assembled} 8 \mathrm{~nm} \mathrm{Ag} \mathrm{NPs.} \mathrm{This}$ implies a greater degree of ligand interdigitation for the assembled $4 \mathrm{~nm} \mathrm{Ag} \mathrm{NPs}$. 

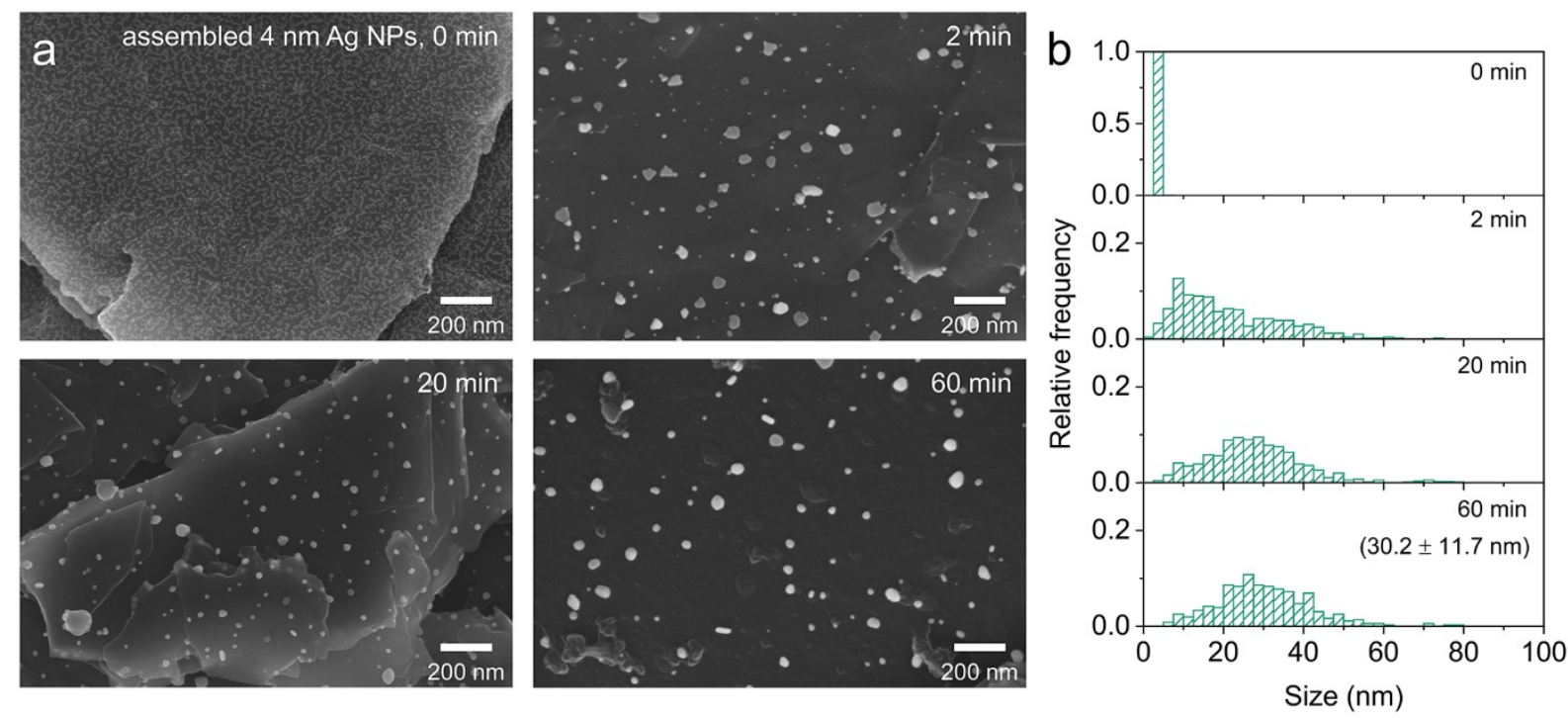

Figure S11. a, b, Structural evolution of assembled $4 \mathrm{~nm} \mathrm{Ag} \mathrm{NPs} \mathrm{(a)} \mathrm{and} \mathrm{size} \mathrm{distribution} \mathrm{of} \mathrm{Ag}$ particles (b) at various time points during $\mathrm{CO}_{2}$ electrolysis at $-0.68 \mathrm{~V}$ vs. RHE. The assembled 4 $\mathrm{nm}$ Ag NPs showed rapid NP coalescence and growth under bias. 

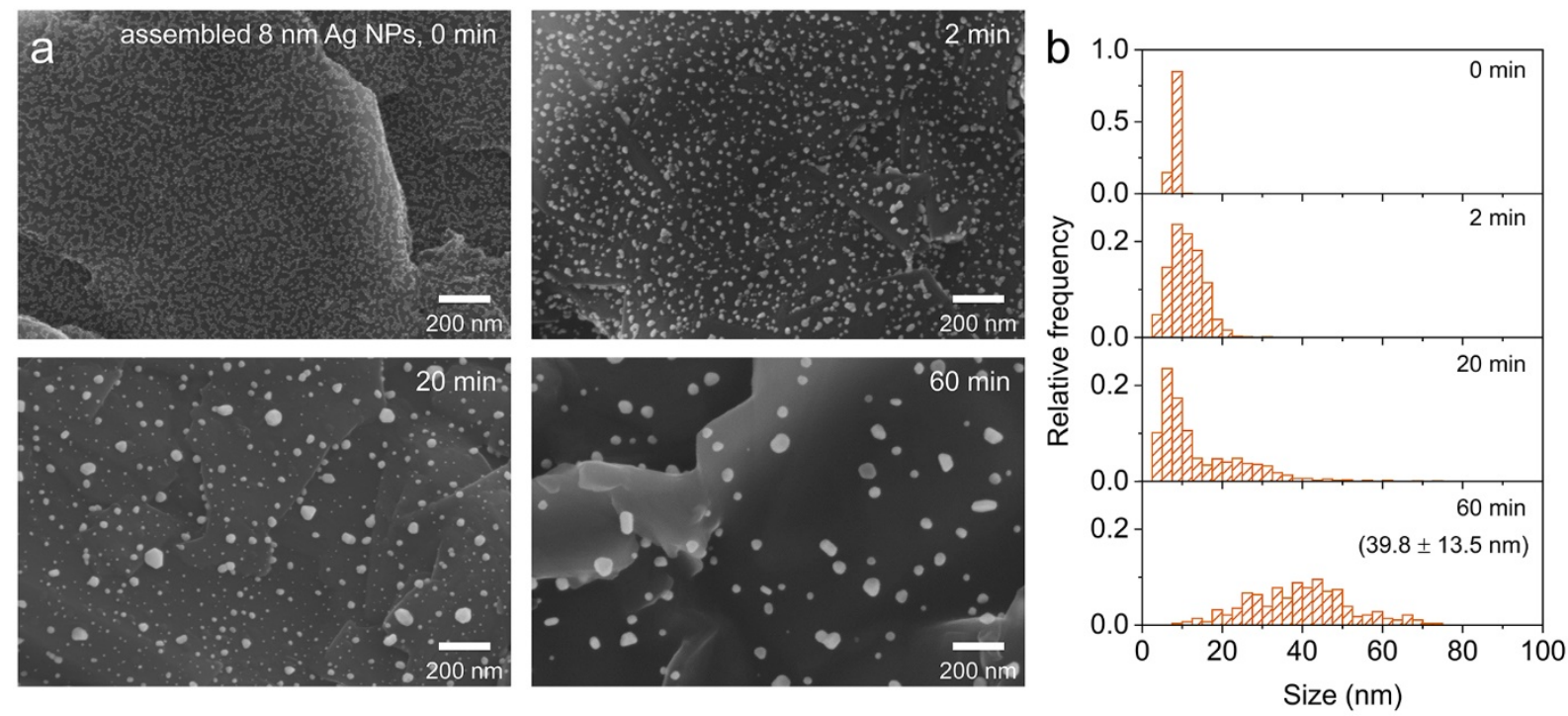

Figure S12. a, b, Structural evolution of assembled $8 \mathrm{~nm} \mathrm{Ag} \mathrm{NPs} \mathrm{(a)} \mathrm{and} \mathrm{size} \mathrm{distribution} \mathrm{of} \mathrm{Ag}$ particles (b) at various time points during $\mathrm{CO}_{2}$ electrolysis at $-0.68 \mathrm{~V}$ vs. RHE. Overall, structural evolution of the assembled $8 \mathrm{~nm} \mathrm{Ag} \mathrm{NPs} \mathrm{was} \mathrm{found} \mathrm{to} \mathrm{be} \mathrm{far} \mathrm{more} \mathrm{sluggish} \mathrm{compared} \mathrm{to} \mathrm{that} \mathrm{of}$ assembled $4 \mathrm{~nm}$ Ag NPs. For instance, at 2 min, small particles with elongated shapes as a result of particle necking are commonly observed. Also, at $20 \mathrm{~min}$, small particles $(<20 \mathrm{~nm})$ were still observed, resulting in a bimodal particle size distribution. 

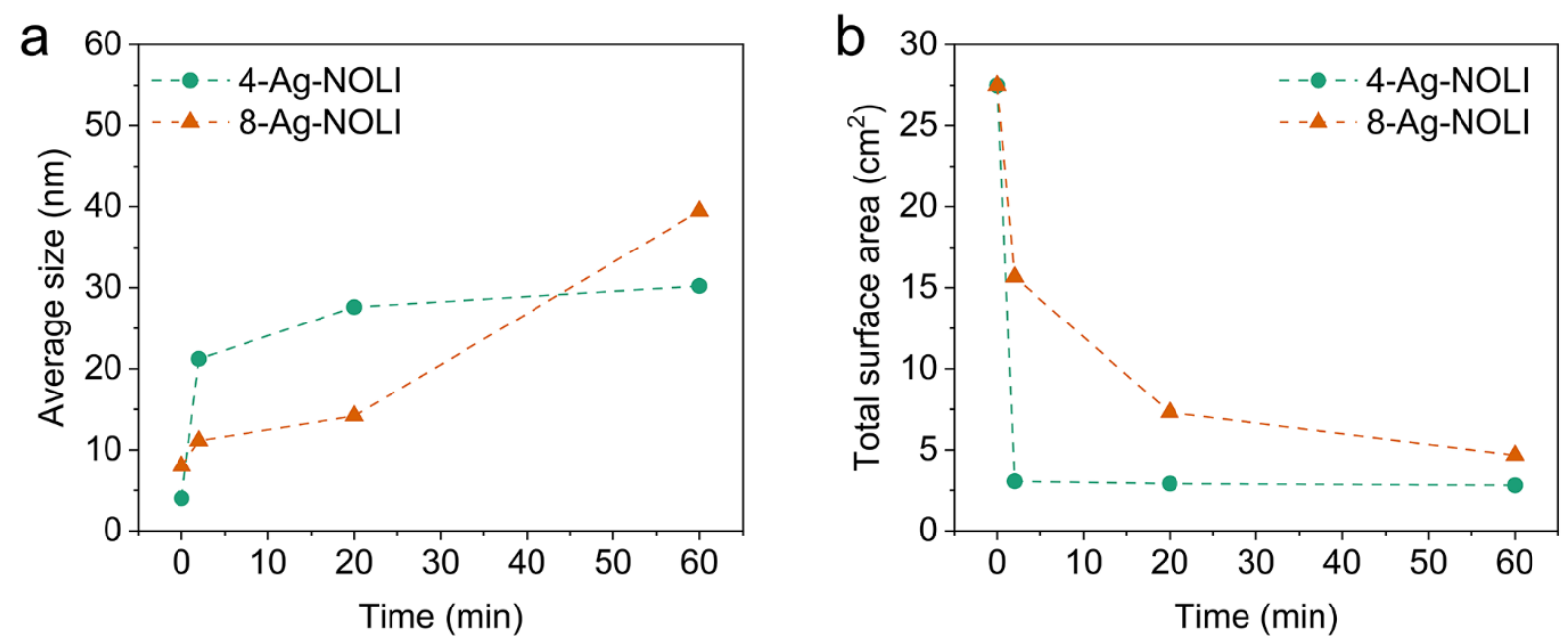

Figure S13. a, b, Average particle size (a) and total particle surface area (b) of 4-Ag-NOLI and 8-Ag-NOLI at various time points during $\mathrm{CO}_{2}$ electrolysis at $-0.68 \mathrm{~V}$ vs. RHE. The average particle size and the total particle surface area were directly calculated from the size distribution of the particles (Figures S11, S12). Assembled $4 \mathrm{~nm} \mathrm{Ag} \mathrm{NPs} \mathrm{exhibited} \mathrm{a} \mathrm{rapid} \mathrm{decrease} \mathrm{in} \mathrm{total}$ particle surface area due to their rapid particle fusion upon the collective dissociation of surface ligands under bias. On the other hand, incomplete reductive ligand dissociation found in the assembled $8 \mathrm{~nm} \mathrm{Ag} \mathrm{NPs} \mathrm{resulted} \mathrm{in} \mathrm{a} \mathrm{more} \mathrm{gradual} \mathrm{decrease} \mathrm{in} \mathrm{total} \mathrm{particle} \mathrm{surface} \mathrm{area.}$ 

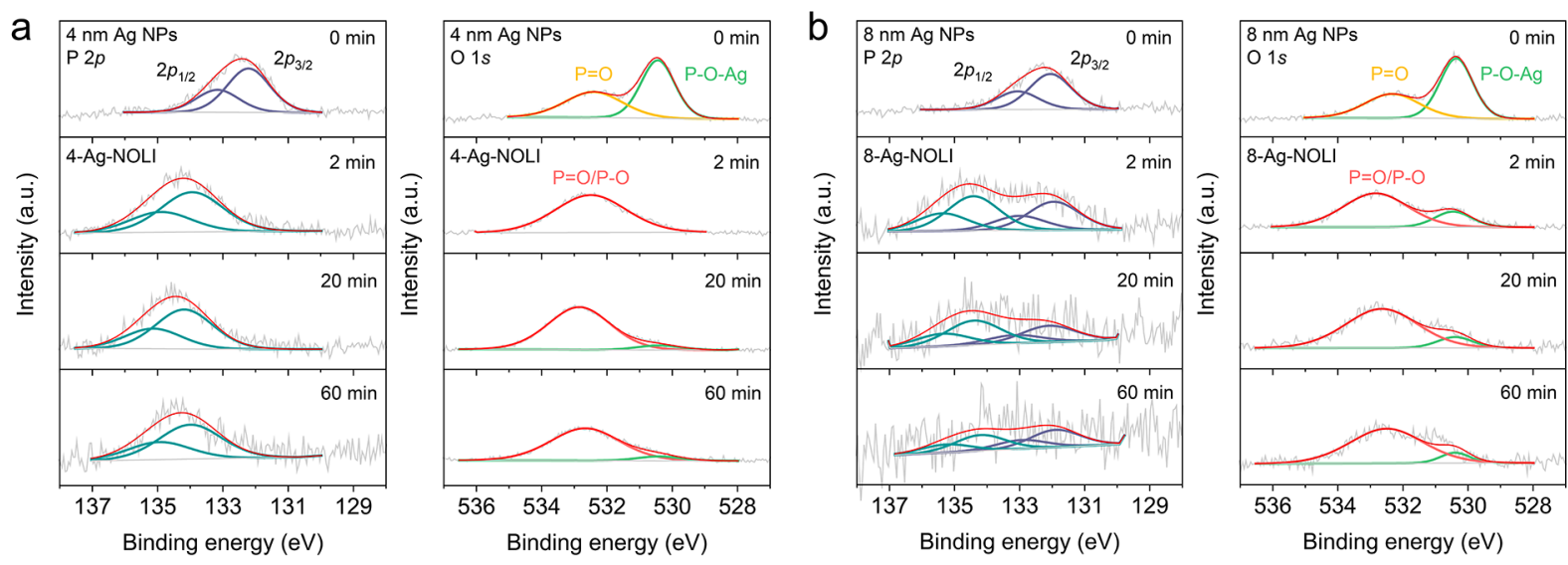

Figure S14. a, b, P $2 p$ and O $1 s$ XPS spectra of assembled $4 \mathrm{~nm}$ (a) and $8 \mathrm{~nm}$ (b) Ag NPs and resultant 4-Ag-NOLI (a) and 8-Ag-NOLI (b) catalysts at different time points during $\mathrm{CO}_{2}$ electrolysis ( $-0.68 \mathrm{~V}$ vs. RHE). Purple peaks in P $2 p$ XPS spectra represent the chemisorbed state of ligands, while cyan peaks represent the physisorbed state. Similarly, green peaks (P-O-Ag) in $\mathrm{O} 1 s$ XPS spectra indicate the chemisorbed ligand state, while pink peaks $(\mathrm{P}=\mathrm{O} / \mathrm{P}-\mathrm{O})$ represent the physisorbed state. This time-dependent XPS result clearly show that the initially chemisorbed ligands collectively detach from the NP surface under bias for the assembled $4 \mathrm{~nm} \mathrm{Ag} \mathrm{NPs} \mathrm{(a).} \mathrm{In}$ contrast, partial ligand dissociation is observed for the assembled $8 \mathrm{~nm} \mathrm{Ag} \mathrm{NPs,} \mathrm{and} \mathrm{some} \mathrm{fraction}$ of the ligands remains chemisorbed throughout $\mathrm{CO}_{2}$ electrolysis (b). 

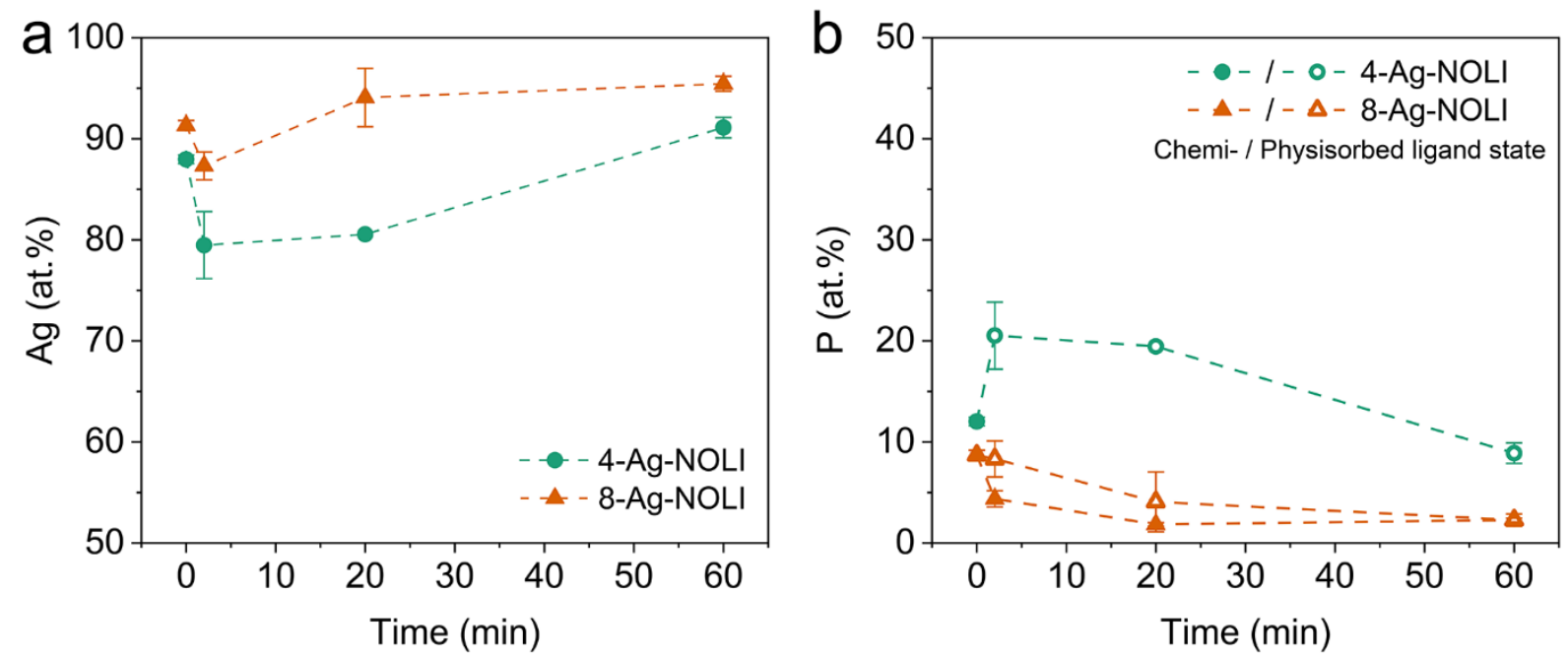

Figure S15. a, b, Ag and $\mathrm{P}$ atomic percent measured from XPS at various time points during $\mathrm{CO}_{2}$ electrolysis at $-0.68 \mathrm{~V}$ vs. RHE. The binding state of ligands was determined by deconvoluting the P $2 p$ XPS spectra (Figure S14). 


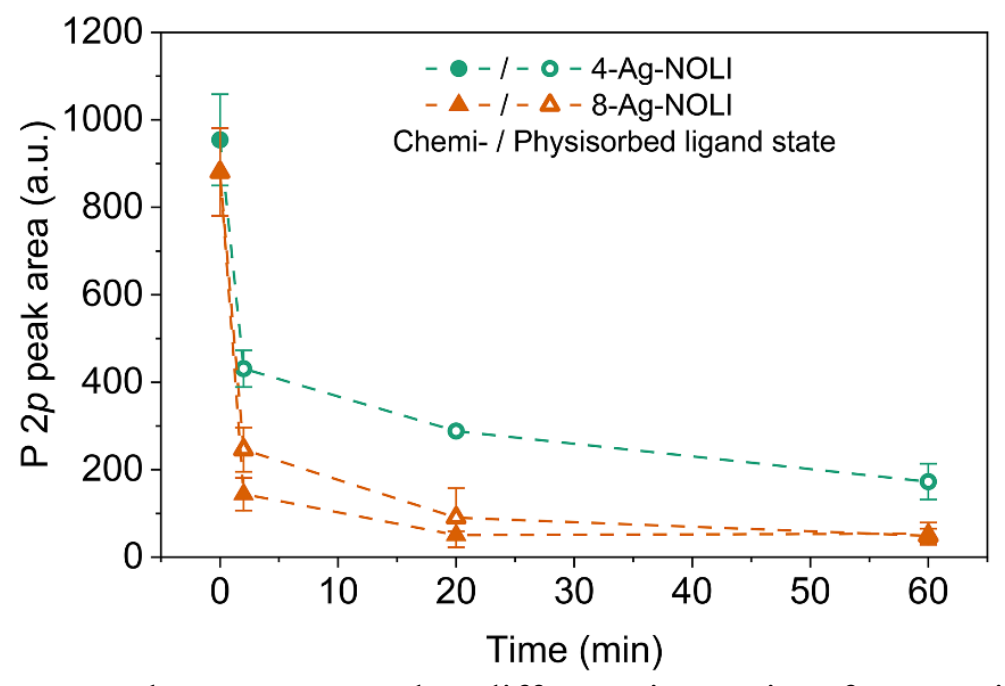

Figure S16. P $2 p$ XPS peak area measured at different time points for quantitative comparison. Solid and open symbols indicate chemisorbed and physisorbed ligand states, respectively. Initially, the TDPA ligands are all chemisorbed on the pristine Ag NPs. 

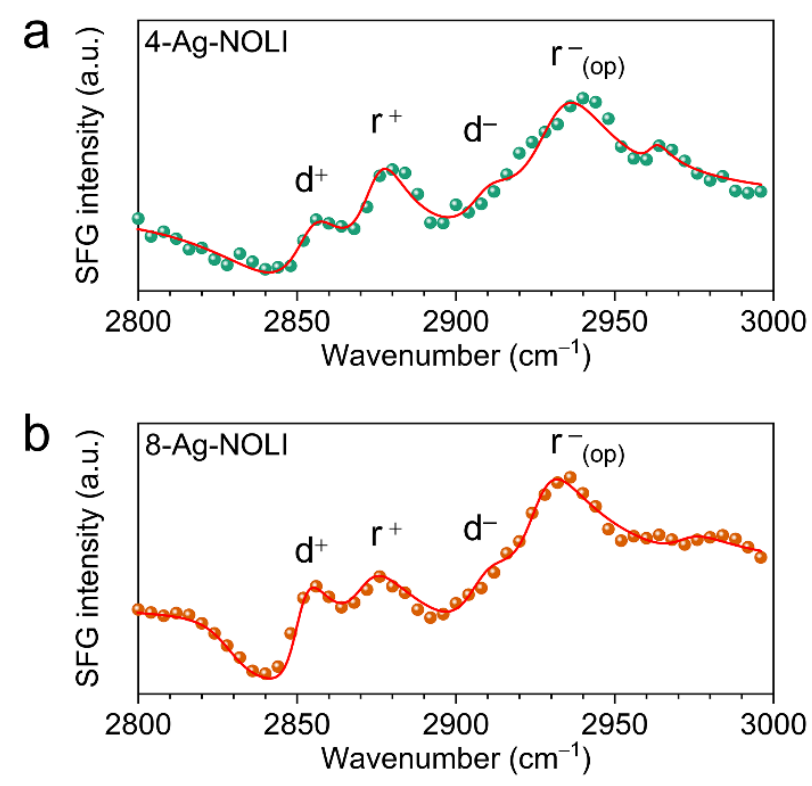

Figure S17. a, b, SFG spectra of 4-Ag-NOLI (a) and 8-Ag-NOLI (b) after one-hour $\mathrm{CO}_{2}$ electrolysis at $-0.68 \mathrm{~V}$ vs. RHE. Solid red curves are fitted lines. The relative intensity ratio of $\mathrm{d}^{+}$ to $\mathrm{r}^{+}$for $4-\mathrm{Ag}-\mathrm{NOLI}$ is evidently much lower than that for 8-Ag-NOLI. This signifies that the structural order of the ligand layer formed in 4-Ag-NOLI is well maintained during $\mathrm{CO}_{2}$ electrolysis compared to 8-Ag-NOLI. 
a

Monolayer config.

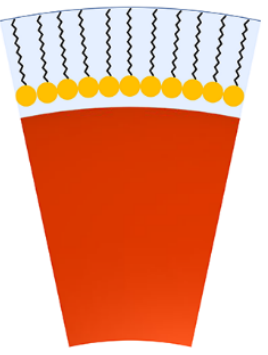

Bilayer config.

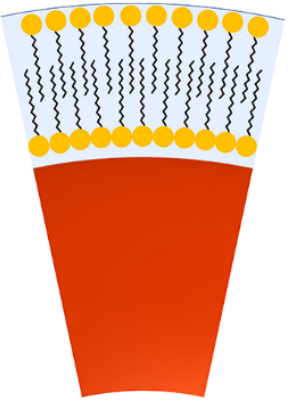

b

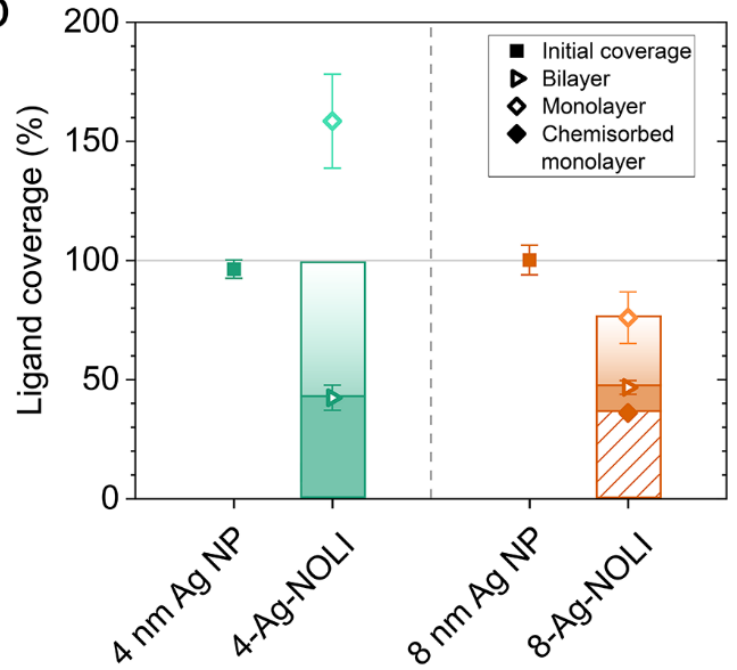

Figure S18. a, Model structure of ligand layer configurations used to estimate ligand coverage from XPS results: the monolayer and bilayer configuration. b, Ligand coverage on pristine 4 and $8 \mathrm{~nm}$ Ag NPs, and Ag-NOLI catalysts after one-hour $\mathrm{CO}_{2}$ electrolysis at $-0.68 \mathrm{~V}$ vs. RHE. Shaded area indicates the ligand layer coverage when physisorbed bilayer configuration is assumed, while shaded area with gradient indicates the potential ligand coverage with a mixed physisorbed bilayer and monolayer configuration assumed. Note that for 8-Ag-NOLI, the ligand coverage shown here is cumulative. That is, the ligand coverage from chemisorbed ligands (hatched area) is added to the ligand coverage from the physisorbed ligand layer (shaded area) to show the total ligand coverage.

For the ligand coverage estimation, the relative atomic ratio of $\mathrm{Ag}$ to $\mathrm{P}$ was used (Figure S15). Spherical particle shape was assumed for both pristine Ag NPs and Ag-NOLI catalysts after $\mathrm{CO}_{2}$ electrolysis. We further assumed that the Ag particles are all enclosed by (111) facets, and the interplanar distance of $\operatorname{Ag}(111)$ was used when considering the exponential decay of photoelectron intensity. Also, the size distributions (Figures S11, S12) were used to take into account the radial decrease in number of atoms for the Ag NP core. The chain length of TDPA ligand and the footprint of phosphonate head group used were $2 \mathrm{~nm}$ and $27 \AA^{2}$, respectively. ${ }^{2}$ The theoretical maximum surface $\mathrm{Ag} / \mathrm{P}$ ratio, obtained by considering the planar atomic density of $\mathrm{Ag}(111)$ and the footprint of TPDA, was used as a reference value for complete ligand coverage (100\%) to estimate the actual ligand coverage for pristine Ag NPs and Ag-NOLI catalysts. The experimental surface $\mathrm{Ag} / \mathrm{P}$ ratio was derived from the XPS results, taking into account the ligand layer model structures and other aforementioned assumptions.

For the pristine 4 and $8 \mathrm{~nm} \mathrm{Ag} \mathrm{NPs,} \mathrm{monolayer} \mathrm{configuration} \mathrm{was} \mathrm{assumed} \mathrm{to} \mathrm{obtain} \mathrm{the} \mathrm{initial}$ ligand coverage (solid square symbols in b). For the ligand layer of the Ag-NOLI catalysts, both monolayer and bilayer configurations were considered as upper and lower boundary conditions. Due to the partial transformation of the NP ligands in the assembled $8 \mathrm{~nm} \mathrm{Ag} \mathrm{NPs,} \mathrm{the} \mathrm{effective}$ NOLI area of 8-Ag-NOLI should be lower compared to 4-Ag-NOLI. 

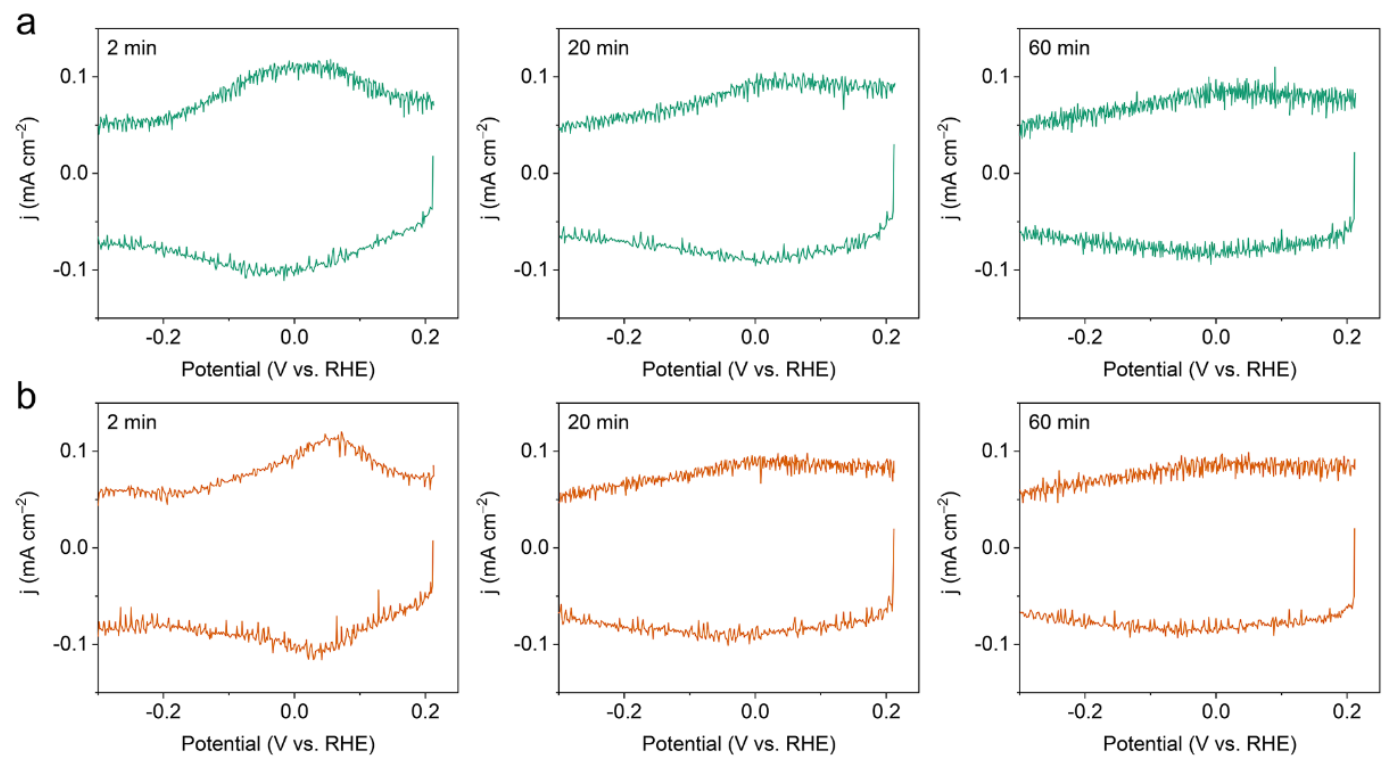

Figure S19. a, b, CV scans of 4-Ag-NOLI (a) and 8-Ag-NOLI (b) at various time points during $\mathrm{CO}_{2}$ electrolysis at $-0.68 \mathrm{~V}$ vs. RHE. The adsorption/desorption features at $2 \mathrm{~min}$ are most pronounced and distinctive, which is likely related to the differences in surface facets available for ligand adsorption at an early stage of NP coalescence. However, the adsorption/desorption peaks become broad as the particles grow and reach a steady state. More importantly, the large current density width of the CVs associated with capacitive charge was well retained throughout $\mathrm{CO}_{2}$ electrocatalysis, and this is further discussed later when addressing pseudocapacitive characteristic of the NOLI. 
a
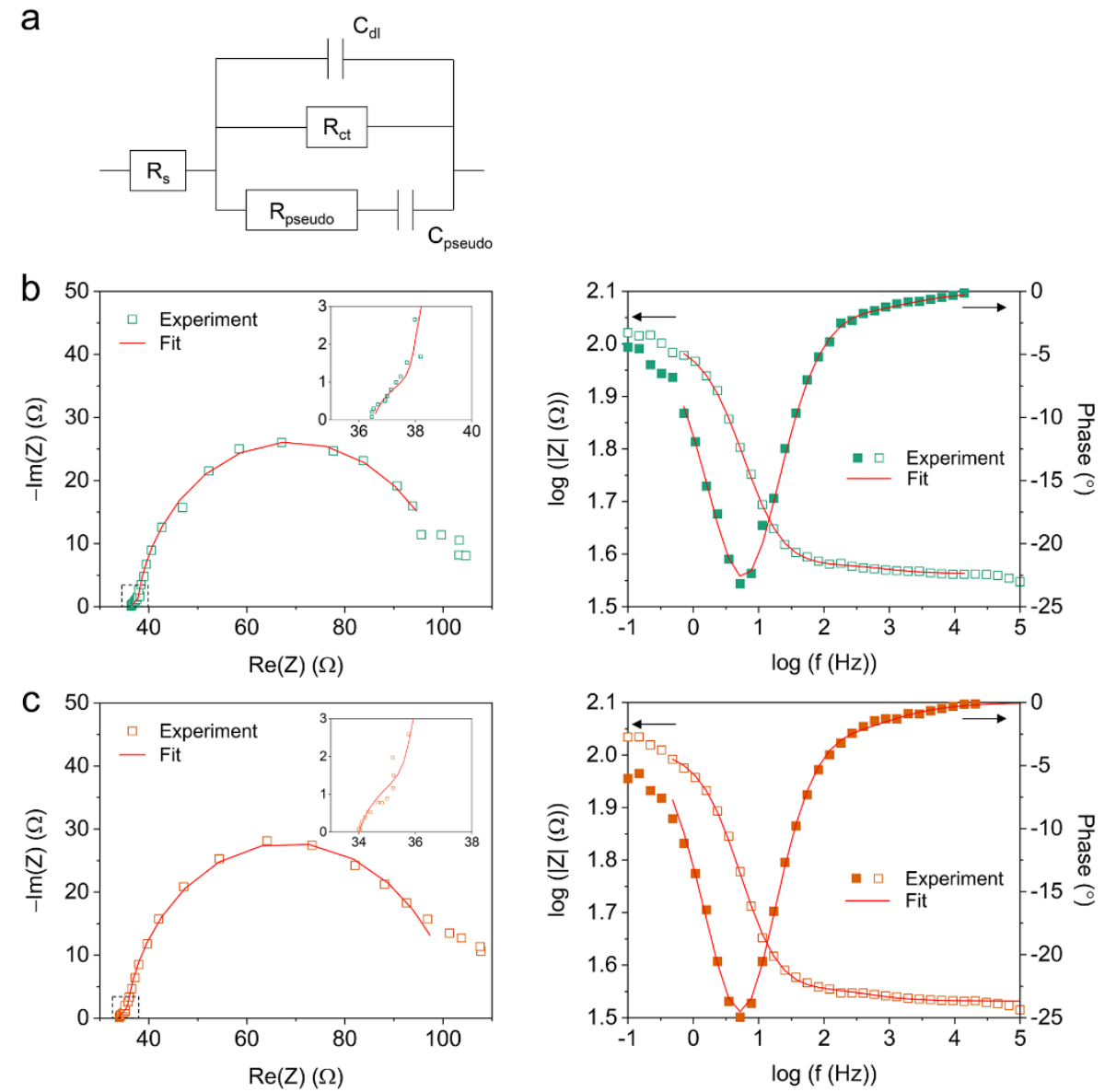

Figure S20. a, Equivalent circuit diagram used for EIS data fitting. b, c, Nyquist and Bode plots of 4-Ag-NOLI (b) and 8-Ag-NOLI (c). Insets are the high frequency region of the Nyquist plots, which displays a semi-circle, indicative of the pseudocapacitive characteristic of the NOLI. ${ }^{1}$ 

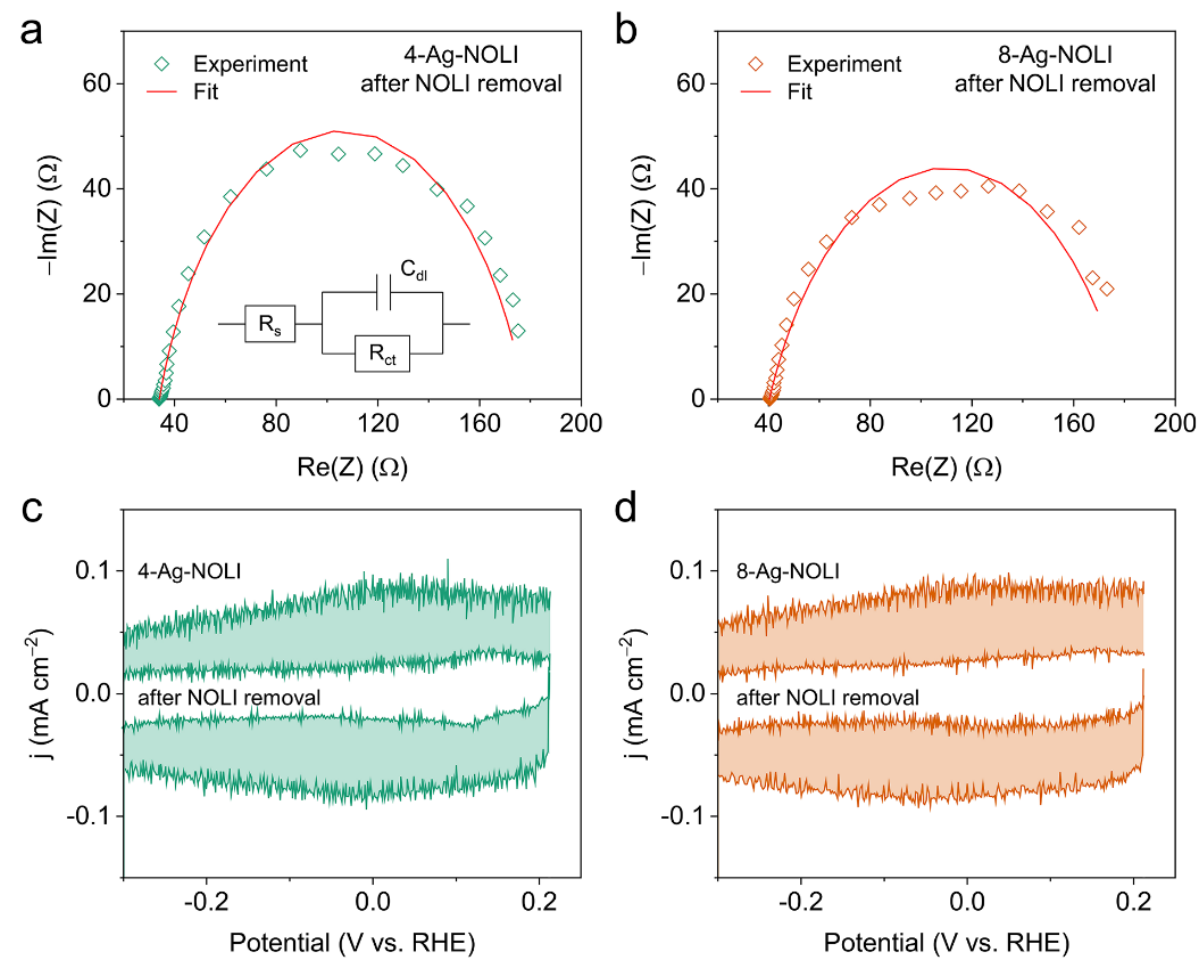

Figure S21. a, b, Nyquist plots after the NOLI was removed from 4-Ag-NOLI and 8-Ag-NOLI. c, d, CV scans of 4-Ag-NOLI and 8-Ag-NOLI before and after the removal of the NOLI. For the NOLI removed catalysts, a three-element equivalent circuit of a typical electrolyte/electrode interface was used for the data fitting (i.e., $R_{s}+C_{d l} / R_{c t}$, inset in a). Here, the double layer capacitance here $\left(\mathrm{C}_{\mathrm{dl}}\right)$ is the sum of capacitive contributions from the carbon paper support and the NOLI removed, bare Ag particles. Importantly, after the NOLI removal, the Nyquist plots did not display the distinct semi-circle in the high frequency region, suggesting a loss of the pseudocapacitive electrochemical interface. In addition, the shaded area in the CV scans clearly indicates a substantial reduction in capacitive charge when the pseudocapacitive NOLI is removed from the Ag-NOLI catalysts. 


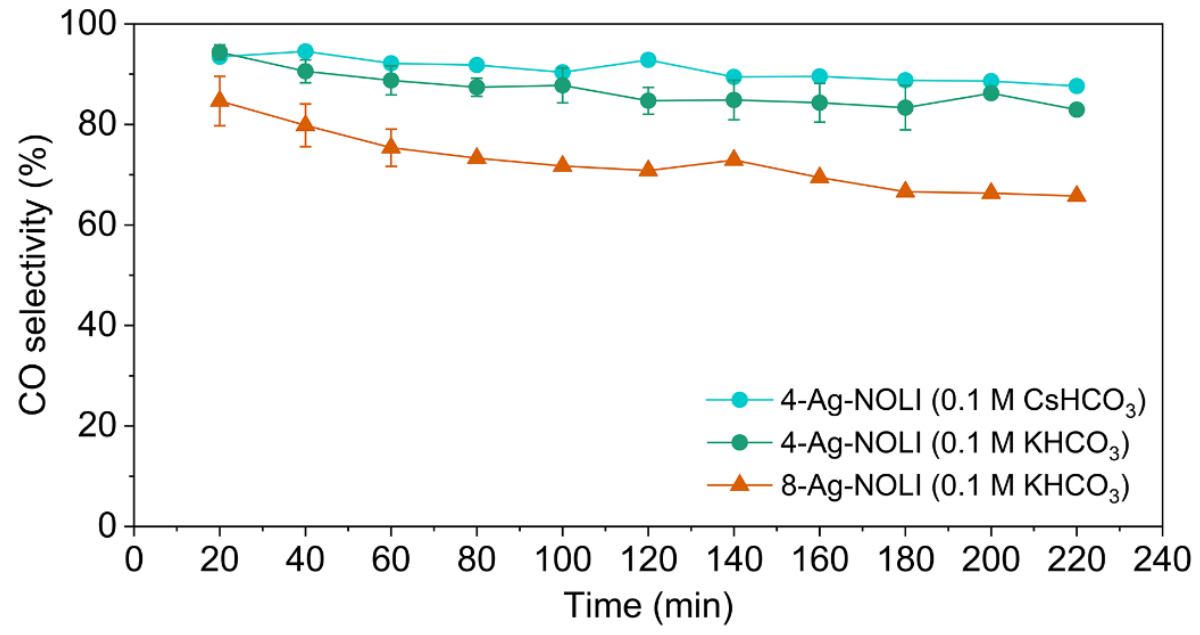

Figure S22. Catalytic stability comparison for $\mathrm{CO}_{2}$ electrocatalysis tested at $-0.68 \mathrm{~V}$ vs. RHE. 4Ag-NOLI showed more stable catalytic performance owing to its stable ligand layer and the NOLI created, whereas 8-Ag-NOLI was less stable, showing a decrease in CO selectivity over time. As previously demonstrated, ${ }^{1}$ various electrolyte cations (e.g., $\mathrm{Cs}^{+}$) can be employed for the NOLI catalysts. 4-Ag-NOLI exhibited improved $\mathrm{CO}$ selectivity in $0.1 \mathrm{M} \mathrm{CsHCO}_{3}$ due to its smaller hydration energy and therefore facile insertion into the NOLI, stabilizing adsorbed $\mathrm{CO}_{2}$ molecules through electrostatic interactions. ${ }^{1,8}$ 
Table S1. Faradaic efficiencies (FEs) and CO selectivity of 4-Ag-NOLI and 8-Ag-NOLI tested at a range of applied potentials in $0.1 \mathrm{M} \mathrm{KHCO}_{3}$.

\begin{tabular}{ccccc}
\hline \multicolumn{5}{c}{ 4-Ag-NOLI } \\
\hline Potential (V vs. RHE) & CO FE (\%) & $\mathrm{H}_{2}$ FE (\%) & Total FE (\%) & CO selectivity (\%) \\
\hline-0.49 & 43.2 & 18.9 & 62.2 & 69.6 \\
\hline-0.54 & 57.4 & 14.6 & 71.9 & 79.7 \\
\hline-0.58 & 63.3 & 11.1 & 74.4 & 85.0 \\
\hline-0.63 & $83.9 \pm 1.6$ & $11.6 \pm 3.7$ & $95.5 \pm 4.0$ & $88.0 \pm 3.4$ \\
\hline-0.68 & $86.6 \pm 6.8$ & $10.0 \pm 1.4$ & $96.6 \pm 6.9$ & $89.7 \pm 1.5$ \\
\hline-0.72 & 92.5 & 5.9 & 98.5 & 94.0 \\
\hline-0.81 & 89.5 & 5.3 & 94.8 & 94.4 \\
\hline-0.89 & 93.0 & 7.1 & 100.1 & 92.9 \\
\hline
\end{tabular}

\begin{tabular}{ccccc}
\hline \multicolumn{5}{c}{ 8-Ag-NOLI } \\
\hline Potential (V vs. RHE) & CO FE (\%) & $\mathrm{H}_{2}$ FE (\%) & Total FE (\%) & CO selectivity (\%) \\
\hline-0.49 & 45.6 & 22.1 & 67.7 & 67.3 \\
\hline-0.54 & 56.4 & 24.0 & 80.4 & 70.1 \\
\hline-0.58 & 58.8 & 23.3 & 82.0 & 71.6 \\
\hline-0.63 & $68.3 \pm 9.9$ & $24.9 \pm 7.1$ & $93.2 \pm 4.1$ & $73.1 \pm 8.5$ \\
\hline-0.68 & $79.6 \pm 5.1$ & $18.5 \pm 4.7$ & $98.1 \pm 4.8$ & $81.2 \pm 4.4$ \\
\hline-0.72 & 84.9 & 12.6 & 97.5 & 87.1 \\
\hline-0.81 & 96.8 & 4.5 & 101.3 & 95.6 \\
\hline-0.88 & 97.2 & 2.2 & 99.4 & 97.8 \\
\hline
\end{tabular}

Note that total FEs at relatively positive potentials $(>-0.60 \mathrm{~V}$ vs. RHE) tend to be low compared to those at more negative potentials due to low absolute currents, which hamper the gas collection efficiency in a real-time gas product measurement from a gas chromatograph. The total FEs improve as currents increase at relatively more negative potentials. 
Table S2. $\mathrm{d}^{+}\left(\mathrm{CH}_{2}\right.$ symmetric stretch) and $\mathrm{r}^{+}\left(\mathrm{CH}_{3}\right.$ symmetric stretch) peak positions in $\mathrm{SFG}$ spectra, and their intensity ratios for isolated and assembled Ag NPs.

\begin{tabular}{cccc}
\hline & $\mathrm{d}^{+}\left(\mathrm{cm}^{-1}\right)$ & $\mathrm{r}^{+}\left(\mathrm{cm}^{-1}\right)$ & $\mathrm{d}^{+} / \mathrm{r}^{+}$ \\
\hline Isolated 4 nm Ag NPs & $2853.2 \pm 1.6$ & $2874.5 \pm 4.0$ & $1.13 \pm 0.08$ \\
\hline Assembled 4 nm Ag NPs & $2854.4 \pm 1.7$ & $2876.7 \pm 1.4$ & $0.56 \pm 0.10$ \\
\hline Isolated 8 nm Ag NPs & $2852.5 \pm 1.3$ & $2873.7 \pm 2.2$ & $0.74 \pm 0.02$ \\
\hline Assembled 8 nm Ag NPs & $2854.2 \pm 0.8$ & $2873.4 \pm 1.7$ & $0.63 \pm 0.09$ \\
\hline
\end{tabular}

Although the ratio of $\mathrm{d}^{-}\left(\mathrm{CH}_{2}\right.$ asymmetric stretch) to $\mathrm{r}_{(\text {op })}^{-}\left(\mathrm{CH}_{3}\right.$ asymmetric out-of-plane stretch) can also be used to gauge structural order of ligand alkane chains, ${ }^{3}$ the ratio of $\mathrm{d}^{+} / \mathrm{r}^{+}$was used in this study, as their peak positions and amplitudes can be more reliably determined. 
Table S3. Impedance data fitting results for Ag-NOLI catalysts using a five-element equivalent circuit, $\mathbf{R s}_{\mathbf{s}}+\mathbf{C d l}_{\mathrm{dl}} / \mathbf{R}_{\mathrm{ct}} \mathrm{(}\left(\mathbf{C}_{\text {pseudo }}+\mathbf{R}_{\text {pseudo }}\right)$.

\begin{tabular}{cccccc}
\hline & $\mathrm{R}_{\mathrm{s}}(\Omega)$ & $\mathrm{C}_{\mathrm{dl}}(\mu \mathrm{F})$ & $\mathrm{R}_{\mathrm{ct}}(\Omega)$ & $\mathrm{C}_{\text {pseudo }}\left(\mu \mathrm{F} / \mathrm{cm}^{2}\right)$ & $\mathrm{R}_{\text {pseudo }}(\Omega)$ \\
\hline 4-Ag-NOLI & $35.4 \pm 1.0$ & $319.7 \pm 21.8$ & $67.9 \pm 6.4$ & $210.4 \pm 36.6$ & $3.4 \pm 0.3$ \\
\hline 8-Ag-NOLI & $33.2 \pm 1.4$ & $355.7 \pm 62.6$ & $96.6 \pm 34.0$ & $93.6 \pm 34.3$ & $3.5 \pm 0.2$ \\
\hline
\end{tabular}

Equivalent circuit diagram used for impedance data fitting can be found in Figure 7a inset and S20a. Due to a major contribution from the carbon paper support to the double layer capacitance $\left(\mathrm{C}_{\mathrm{dl}}\right)$, absolute values (i.e., $\left.\mu \mathrm{F}\right)$ are tabulated for double layer capacitance, while specific pseudocapacitance $\left(\mathrm{C}_{\text {pseudo }}\right)$ values (i.e., $\left.\mu \mathrm{F} / \mathrm{cm}^{2}\right)$ are listed, which specifically originates from $\mathrm{Ag}$ NOLI. The area used for specific pseudocapacitance calculation was obtained by Pb UPD after ligand layer removal to account for all the physical surface area of the Ag particles. Therefore, the specific capacitance values can be used to compare the structural details of the NOLI for the AgNOLI catalysts. 


\section{References}

1. Kim, D.; Yu, S.; Zheng, F.; Roh, I.; Li, Y.; Louisia, S.; Qi, Z.; Somorjai, G. A.; Frei, H.; Wang, L.-W.; Yang, P., Selective $\mathrm{CO}_{2}$ electrocatalysis at the pseudocapacitive nanoparticle/ordered-ligand interlayer. Nat. Energy 2020, 5 (12), 1032-1042.

2. Hauffman, T.; Blajiev, O.; Snauwaert, J.; van Haesendonck, C.; Hubin, A.; Terryn, H., Study of the self-assembling of n-octylphosphonic acid layers on aluminum oxide. Langmuir 2008, 24 (23), 13450-13456.

3. Weeraman, C.; Yatawara, A. K.; Bordenyuk, A. N.; Benderskii, A. V., Effect of nanoscale geometry on molecular conformation: vibrational sum-frequency generation of alkanethiols on gold nanoparticles. J. Am. Chem. Soc. 2006, 128 (44), 14244-14245.

4. Dalstein, L.; Revel, A.; Humbert, C.; Busson, B., Nonlinear optical response of a gold surface in the visible range: A study by two-color sum-frequency generation spectroscopy. I. Experimental determination. J. Chem. Phys. 2018, 148 (13), 134701.

5. Humbert, C.; Noblet, T.; Dalstein, L.; Busson, B.; Barbillon, G., Sum-Frequency Generation Spectroscopy of Plasmonic Nanomaterials: A Review. Materials 2019, 12 (5), 836.

6. Heinz, H.; Vaia, R. A.; Farmer, B. L., Relation between packing density and thermal transitions of alkyl chains on layered silicate and metal surfaces. Langmuir 2008, 24 (8), 3727-3733.

7. Heinz, H.; Pramanik, C.; Heinz, O.; Ding, Y.; Mishra, R. K.; Marchon, D.; Flatt, R. J.; Estrela-Lopis, I.; Llop, J.; Moya, S.; Ziolo, R. F., Nanoparticle decoration with surfactants: Molecular interactions, assembly, and applications. Surf. Sci. Rep. 2017, 72 (1), 1-58.

8. Garlyyev, B.; Xue, S.; Watzele, S.; Scieszka, D.; Bandarenka, A. S., Influence of the Nature of the Alkali Metal Cations on the Electrical Double-Layer Capacitance of Model Pt(111) and $\mathrm{Au}(111)$ Electrodes. J. Phys. Chem. Lett. 2018, 9 (8), 1927-1930. 